\title{
2-Acetylbenzimidazole: a Valuable Synthon for the Synthesis of Biologically Active Molecules
}

\author{
Gopal Krishna Padhy 1,2,* (D) , Jagadeesh Panda ${ }^{3}$, Saroj K. Raul ${ }^{4}$, Ajaya K. Behera ${ }^{5}$

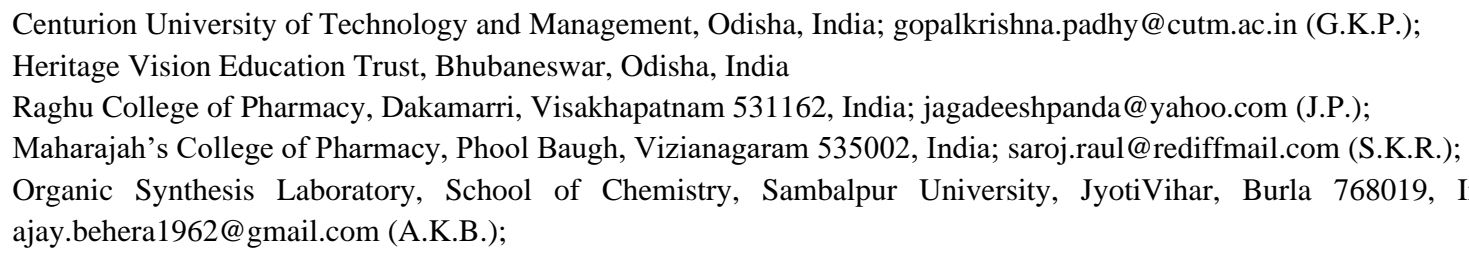

Received: 20.10.2020; Revised: 30.11.2020; Accepted: 4.12.2020; Published: 12.12.2020

\begin{abstract}
Benzimidazole is an important moiety from a medicinal chemistry perspective due to its various biological activities such as antimicrobial, anti-cancer, anti-diabetic, anti-Alzheimers, and antiinflammatory, etc. 2-acetylbenzimidazole is exploited to obtain various heterocyclic compounds of pharmacological interest. This review's main motive is to present the literature on 2acetylbenzimidazole chemistry and provide valuable and up-to-date information for its applications. The present review is carried out by compiling literature from 1964 to 2020 concerning the synthesis and biological aspects of various heterocyclic compounds derived from 2-acetylbenzimidazole. Literature was collected from various online search engines viz. Google Scholar, PubMed, Science Direct, Core, and Semantic scholar. 2-acetylbenzimidazole has been successfully employed as a synthon to obtain heterocyclic system viz. oxirane, pyrazoline, thiazole, pyrazole, isoxazoline, isoxazole, pyridine, pyrimidine, thiazine, diazepine, and other miscellaneous rings. 2acetylbenzimidazole has shown promise for the convenient synthesis of various heterocyclic compounds. The reactions can be carried out on various reactive sites of 2-acetylbenzimidazole, which are the carbonyl group and the amino group. This review will help to explore various heterocyclic compounds and particularly in the synthesis of biologically useful compounds.
\end{abstract}

Keywords: 2-Acetylbenzimidazole; chalcone; pyrazoline; pharmacology; synthesis.

(C) 2020 by the authors. This article is an open-access article distributed under the terms and conditions of the Creative Commons Attribution (CC BY) license (https://creativecommons.org/licenses/by/4.0/).

\section{Introduction}

Benzimidazole, a heterocyclic moiety, consists of benzene and imidazole ring, combined at the $4^{\text {th }}$ and $5^{\text {th }}$ position. It is a very important molecule from a medicinal chemistry perspective due to its numerous pharmacological activities, viz anti-viral [1], antimicrobial [2], anti-diabetic [3], anti-cancer [4,5], anti-Alzheimers [6], anti-inflammatory [7], etc. Due to its numerous biological activities, it is still an exciting area to do research. 2-acetylbenzimidazole is a benzimidazole derivative where the acetyl $\left(-\mathrm{COCH}_{3}\right)$ group is attached at $2^{\text {nd }}$ position. Given the various pharmacological implications of benzimidazole derivatives, as previously mentioned, it inspires to investigate new synthetic protocol for biologically potent benzimidazoles. Several papers have been published over the years, which revealed numerous synthetic methods and pharmacological aspects of benzimidazoles prepared by utilizing 2acetylbenzimidazole as a synthon. The review presented here highlights exclusively describing 
diverse synthetic methods and pharmacological activity of benzimidazole derivatives prepared from the 2-acetylbenzimidazole precursor.

\section{Synthesis of 2-acetylbenzimidazole}

2-acetylbenzimidazole was initially recovered as an impurity during the synthesis 2methylquinoxaline 3 from o-phenylenediamines 1 and pyruvaldehyde $\mathbf{2}$ (Scheme 1). It was independently synthesized from 1'-hydroxyethylbenzimidazole $\mathbf{5}$ under oxidation conditions using chromium trioxide [8] (Scheme 2).

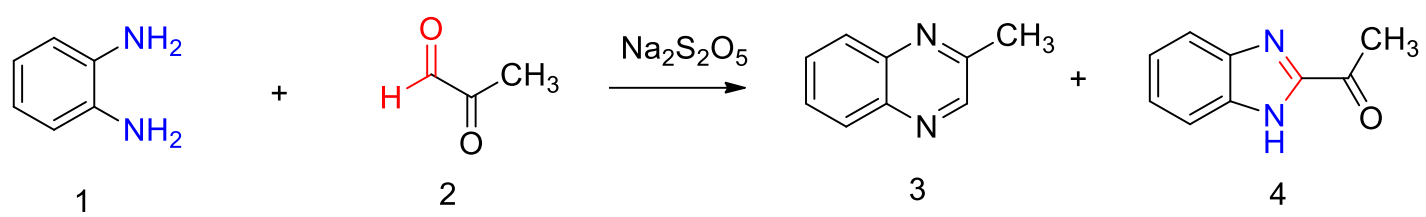

Scheme 1. Preparation of 2-methylquinoxaline and 2-acetylbenzimidazole.<smiles>CC(O)c1nc2ccccc2[nH]1</smiles>

5<smiles>CC(=O)OCC(C)O</smiles>
$90^{\circ} \mathrm{C}$<smiles>CC(=O)c1nc2ccccc2[nH]1</smiles>

Scheme 2. Preparation of 2-acetylbenzimidazole from 1'-hydroxyethylbenzimidazole.

For the bromination study, Ramaiah and co-workers prepared 2-acetylbenzimidazole starting from o-phenylenediamines 1, employing potassium dichromate and diluted $\mathrm{H}_{2} \mathrm{SO}_{4}$ as an oxidizing agent [9] (Scheme 3).<smiles>Nc1ccccc1N</smiles>

1<smiles>CC(O)C(=O)O</smiles>

6<smiles>CC(O)c1nc2ccc(C3CC3)cc2[nH]1</smiles>

5

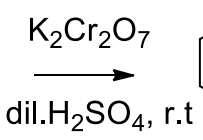

dil. $\mathrm{H}_{2} \mathrm{SO}_{4}$, r.t<smiles>CC(=O)c1nc2ccccc2[nH]1</smiles>

4

Scheme 3. Preparation of 2-acetylbenzimidazole from o-phenylenediamines.

Kalirajan et al. carried out the oxidation of 1'-hydroxyethylbenzimidazole 5 in the presence of $\mathrm{K}_{2} \mathrm{Cr}_{2} \mathrm{O}_{7}$, and $5 \%$ dilute acetic acid to obtain 2-acetylbenzimidazole [10] (Scheme 4).

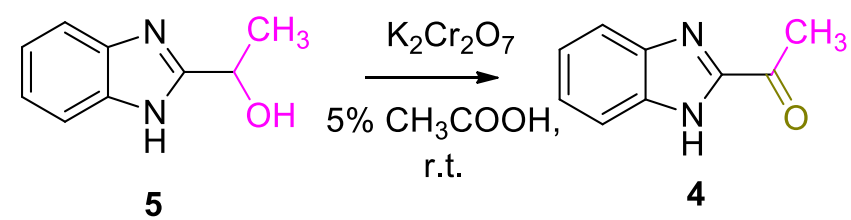

Scheme 4. Preparation of 2-acetylbenzimidazole.

Kumar et al. studied the oxidation of 2-( $\alpha$-hydroxyethyl)benzimidazole to obtain 2acetylbenzimidazole. Various oxidizing agents such as $\mathrm{K}_{2} \mathrm{Cr}_{2} \mathrm{O}_{7}, \mathrm{MnO}_{2}, \mathrm{H}_{2} \mathrm{O}_{2} / \mathrm{gl}$. $\mathrm{AcOH}$, $\mathrm{CaOCl}_{2}, \mathrm{~m}-\mathrm{CPBA}, 10 \% \mathrm{HNO}_{3}, 50 \% \mathrm{HNO}_{3}$, and $\mathrm{CAN}$ were employed for the reaction. Among the oxidizing agents used, $\mathrm{K}_{2} \mathrm{Cr}_{2} \mathrm{O}_{7}, \mathrm{H}_{2} \mathrm{O}_{2} / \mathrm{gl}$. AcOH, CAN were found to be the most effective. It was observed that $\mathrm{K}_{2} \mathrm{Cr}_{2} \mathrm{O}_{7}$ in diluted $\mathrm{H}_{2} \mathrm{SO}_{4}$ gave the highest yield (72\%). Moreover, neutralization of $\mathrm{H}_{2} \mathrm{SO}_{4}$ with $\mathrm{NH}_{3}$ was found to be a crucial step. During the neutralization process, the $\mathrm{pH}$ of the solution should be between 5.5-6.0 and supposed to not go above 7.0. If 
the $\mathrm{pH}$ of the solution exceeds 7.0, then the yield of 2-acetylbenzimidazole decreases considerably [11].

\section{Synthesis of 2-acetylbenzimidazole derivatives}

\subsection{Synthesis of chalcones.}

A series of benzimidazole chalcones 7a-p were synthesized by the Claisen-Schmidt condensation reaction of 2-acetylbenzimidazole 4 with aryl aldehydes (Scheme 5). The compounds were evaluated for their nematicidal activity against Haemonchus contortus. Compound 7a was discovered to be most active ( $\left.\mathrm{LC}_{100}=0.002 \mu \mathrm{g} / \mathrm{mL}\right)[12]$.

Mathew and co-workers have synthesized similar benzimidazole chalcones by microwave and screened them for their antibacterial activity. Compound 7o showed good activity towards Gram-negative bacteria (K. pneumonia and E. coli) and less active towards Gram-negative bacteria. Few derivatives showed modest activity against the fungi [13].

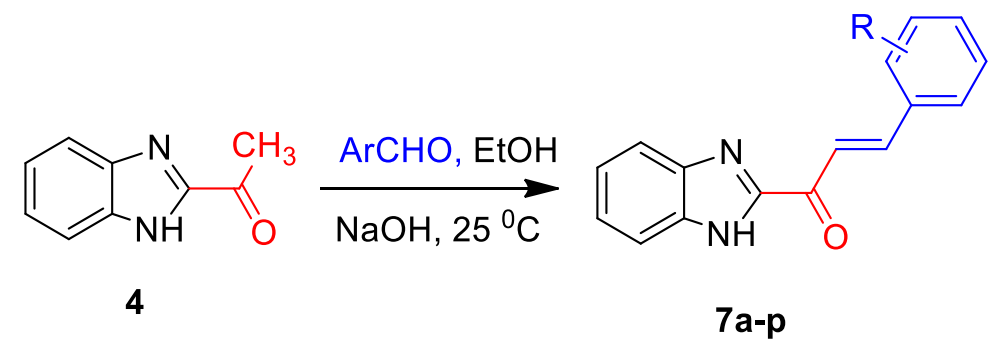

7a-p; R=H, 2-Cl, 3-Cl, 4-Cl, 2- $\mathrm{OCH}_{3}, 3-\mathrm{OCH}_{3}, 4-\mathrm{OCH}_{3}, 2-\mathrm{Br}, 4-\mathrm{F}, 2-\mathrm{CH}_{3}, 3-\mathrm{CH}_{3}, 4-\mathrm{CH}_{3}$, 3- $\mathrm{NO}_{2}, 4-\mathrm{NO}_{2}$, $2-\mathrm{OH}, 3-\mathrm{OH}$

Scheme 5. Synthesis of benzimidazole chalcones 7a-p.

A series of benzimidazole derived chalcones 9a-g were synthesized by condensing 2acetylbenzimidazole with various aldehydes (Scheme 6). The chalcones were evaluated for their in-vitro antimicrobial activity. Synthesized chalcones showed good activity against the gram-positive bacteria and fungal species [14].

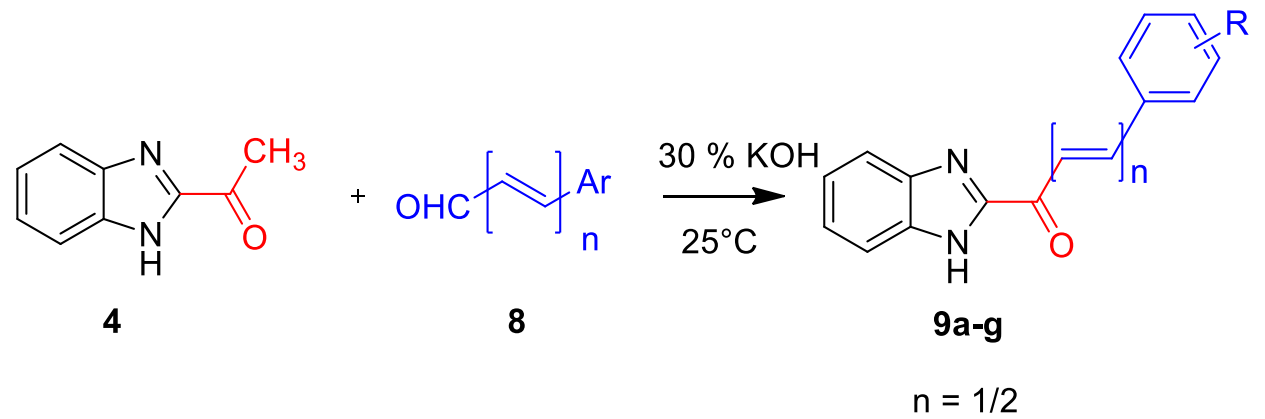

9a-g; R= H, 3- $\mathrm{OCH}_{3}, 4-\mathrm{OCH}_{3}, 2-\mathrm{Cl}, 4-\mathrm{Br}, 4-\mathrm{CH}_{3}$, Furyl

Scheme 6. Synthesis of benzimidazole chalcones 9a-g.

Benzimidazole-pyridine or phenyl ketenes 10a-b were synthesized by Claisen Schmidt reaction of 2-acetyl benzimidazole with aromatic aldehydes. Reduction of the carbonyl function or of the double bond gave compounds 11a-b and 12a-b (Scheme 7). The compounds were screened against cancer cell lines MCF-7, HCT116, and HepG2. Compounds 9a and 9b showed IC50 values of 0.06 and $0.03 \mu \mathrm{M}$ against the HCT116 cancer cell line, respectively. The activity was better than that of 5-Fluorouracil and near to that of Paclitaxel [15]. 


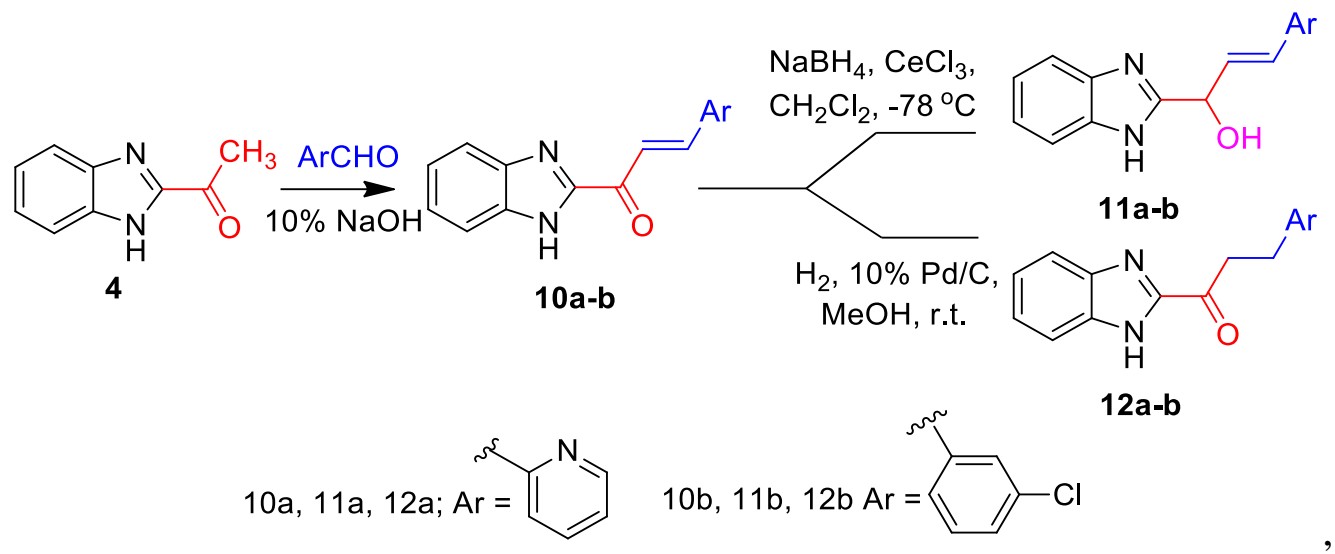

Scheme 7. Synthesis of benzimidazole derivatives 10,11,12-a \& b.

A series of 1-(toluene-4-sulfonyl)-1H-benzimidazol-2-yl]-propen-1-one 14a-f synthesized by tosylation of benzimidazole chalones 13a-f using ultrasound (Scheme 8) compound 14b showed moderate inhibition of enzyme glucoamylase. Compounds $14 \mathbf{c}$ and $\mathbf{1 4 e}$ exhibited excellent activity against different bacteria and fungi Candida albicans [16].

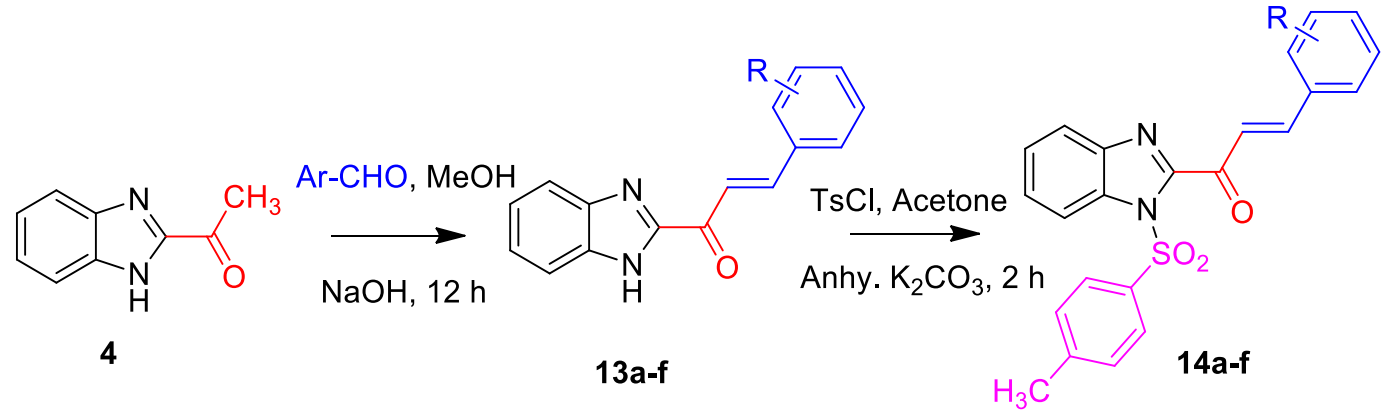

14a-f; $\mathrm{R}=\mathrm{H}, 4-\mathrm{CF}_{3}, 4-\mathrm{OCH}_{3}, 2-\mathrm{Cl}, 4-\mathrm{Cl}, 4-\mathrm{CH}_{3}$

Scheme 8. Synthesis of benzimidazole chalcones 13a-f \& 14a-f.

Benzimidazolylchalcones derivatives 16a-d of chlormidazole were synthesized by reacting different aromatic aldehydes with $N$-(4-chlorobenzyl)-2-acetylbenzimidazole 16 in order to develop new antifungal compounds (Scheme 9). The compounds 17a, 17c, and 17d showed significant antifungal activities against Candida albicans and were found to possess MIQ values of $1.25,5$, and $0.625 \mu \mathrm{g}$, respectively [17].

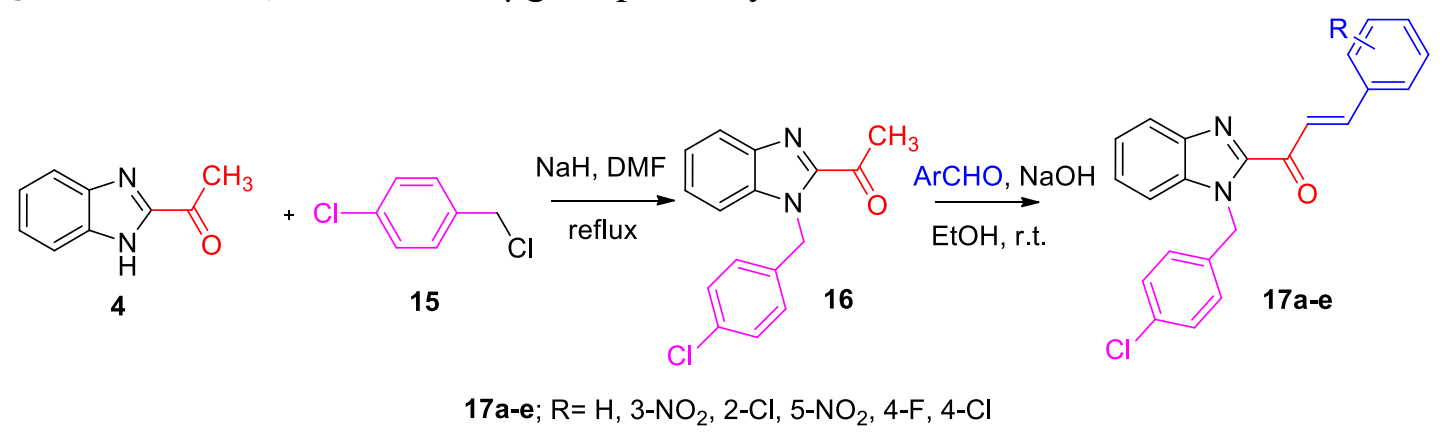

Scheme 9. Synthesis of benzimidazole chalcones 17a-e.

A series of benzimidazole chalcones bearing the oxadiazole ring 20a-e were synthesized by a nucleophilic substitution reaction between benzimidazole chalcones 18a-e and 19 in the presence of $\mathrm{K}_{2} \mathrm{CO}_{3}$ (Scheme 10). The compounds were found to be moderately active against bacteria and fungi [18]. 


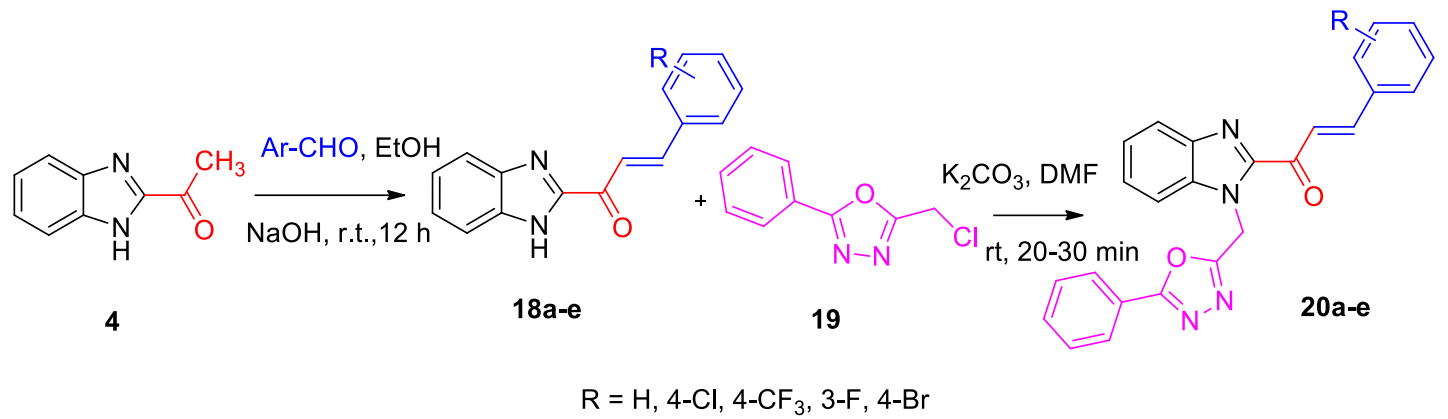

Scheme 10. Synthesis of benzimidazole chalcones 20a-h.

A novel series of 1-benzylbenzimidazole chalcones were synthesized in our laboratory, starting from o-phenylenediamine 1. Chalcones were prepared by Claisen-Schmidt condensation of $\mathbf{4}$ with various aromatic aldehydes in the presence of $\mathrm{NaOH}$. Nucleophilic substitution of 1H-Benzimidazole chalcones 21a-d with benzyl chloride provided the final compounds 23a-d (Scheme 11). Compounds were tested for their antibacterial activity against selective bacteria. Compound $\mathbf{2 3 b}$ was found to be most effective with an $\mathrm{IC}_{50}$ value of 62.5 $\mu \mathrm{g} / \mathrm{mL}[19]$.

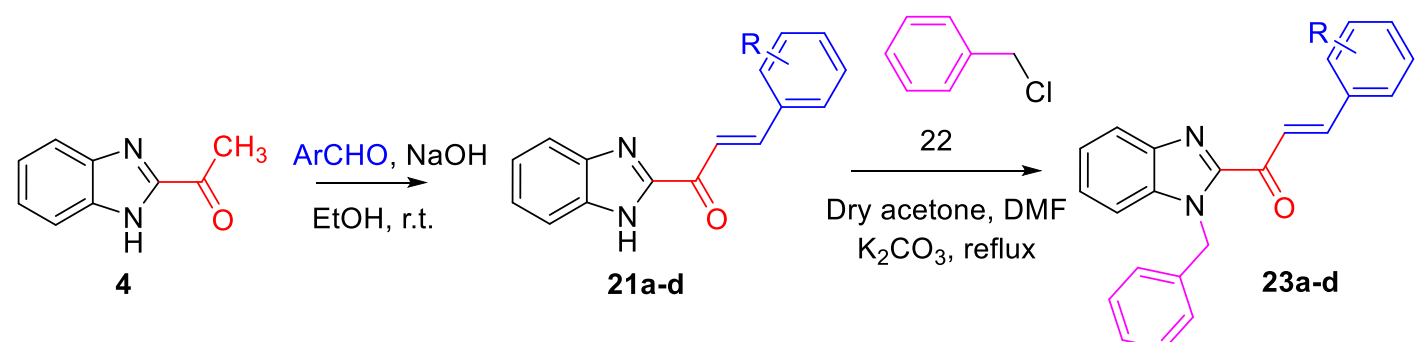

23a-d; $\mathbf{R}=4-\mathrm{N}\left(\mathrm{CH}_{3}\right)_{2}, 3-\mathrm{OCH}_{3}, 3,4-\mathrm{OCH}_{3}, 2-\mathrm{Cl}$

Scheme 11

Scheme 11. Synthesis of benzimidazole chalcones 23a-d.

Benzimidazolylchalcone 25 was prepared by reacting 4 with 2-chloroquinoline-3carbaldehyde $\mathbf{2 4}$ in ethanol and sodium hydroxide at room temperature (Scheme 12) [20].

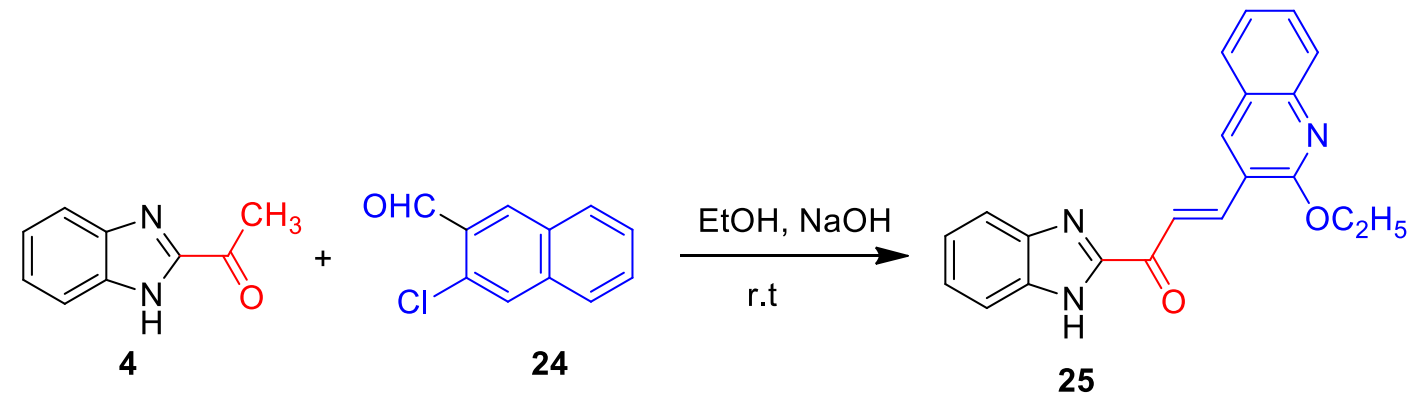

Scheme 12. Synthesis of benzimidazole chalcone 25 .

A series of benzimidazole chalcones bearing aromatic amide substituent (Scheme 13) were synthesized and screened for their anti-cancer activity against cancer cell lines HepG2, HCT116, CRL-5908, and A549. Compounds 29c, 29f and 29i showed good activity against HCT116 cells $\left(\mathrm{IC}_{50}=1.34-1.63 \mu \mathrm{M}\right)$. It was observed that the compounds act by upregulating the expression of TP53 protein in tumor cells without inhibiting the MDM2-TP53 interaction [21]. 
<smiles>CC(=O)c1nc2ccccc2[nH]1</smiles><smiles>[R]c1cccc(NC(=O)c2ccc(/C=C/C(=O)c3nc4ccccc4[nH]3)cc2)c1</smiles>

29a-i<smiles>O=C(O)c1ccc(/C=C/C(=O)c2nc3ccccc3[nH]2)cc1</smiles>

27<smiles>O=C(Cl)c1ccc(/C=C/C(=O)c2nc3ccccc3[nH]2)cc1</smiles>

29a-i; R= H, 2- $\mathrm{CH}_{3}, 3-\mathrm{CH}_{3}, 4-\mathrm{CH}_{3}, 2-\mathrm{Cl}, 3-\mathrm{Cl}, 4-\mathrm{Cl}, 2-\mathrm{OCH}_{3}, 3-\mathrm{OCH}_{3}$

Scheme 13. Synthesis of benzimidazole chalcones $\mathbf{2 9} \mathbf{a}-\mathbf{i}$.

A series of benzimidazole-triazole-hybrid molecules 33a-j were synthesized by the reaction between different azides and benzimidazole alkynes 32a-j bearing a chalcone group (Scheme 14). Evaluation of anti-proliferative activity showed that compound 33j was most active with an $\mathrm{IC}_{50}$ value of $6.23,5.89$, and $10.7 \mu \mathrm{M}$ against T47-D, MDA-MB-231, and PC3 cancer cell line [22].
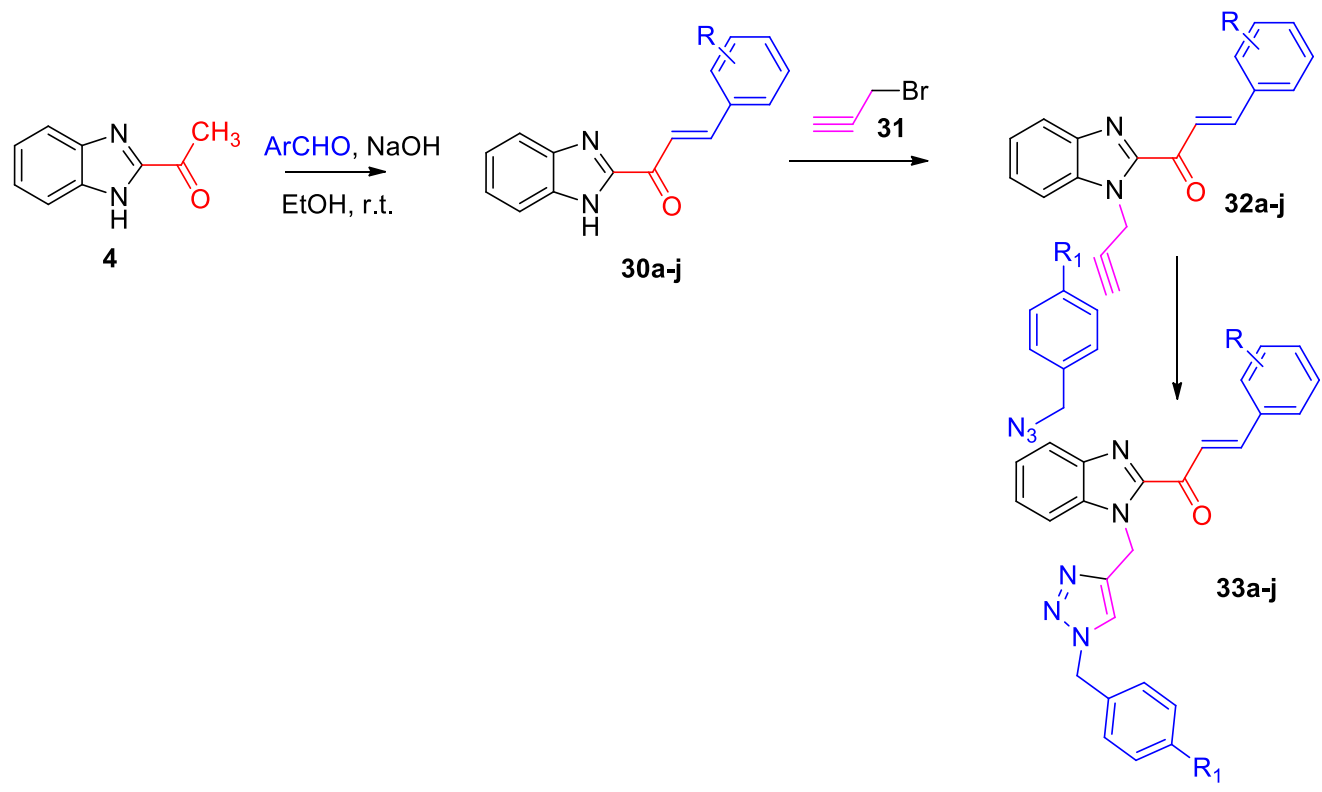

33a; $\mathrm{R}=4-\mathrm{CH}_{3}, \mathrm{R}_{1}=\mathrm{OCH}_{3} 33 \mathrm{~b} ; \mathrm{R}=4-\mathrm{Cl}, \mathrm{R}_{1}=\mathrm{OCH}_{3}$, 33c; $\mathrm{R}=4-\mathrm{Br}, \mathrm{R}_{1}=\mathrm{OCH}_{3}$ 33d; R=4- $\mathrm{CH}_{3}, \mathrm{R}_{1}=\mathrm{H}$ 33e; R=4-Br, $\mathrm{R}_{1}=\mathrm{H}$ 33f; R=4-Cl, $\mathrm{R}_{1}=\mathrm{CH}_{3} 33 \mathrm{~g} ; \mathrm{R}=\mathrm{H}, \mathrm{R}_{1}=\mathrm{CH}_{3}$ 33h; R=4- $\mathrm{Br} \mathrm{R}_{1}=\mathrm{CH}_{3} 33$; $\mathrm{R}=4-\mathrm{OCH} 3$ $\mathrm{R}_{1}=\mathrm{CH}_{3} 33 \mathrm{j} ; \mathrm{R}=2-\mathrm{Cl} \mathrm{R} \mathrm{R}_{1}=\mathrm{H}$

Scheme 14. Synthesis of benzimidazole chalcones 33a-j.

An environment-friendly synthesis of benzimidazole linked indole chalcones 35a-n were prepared by catalyzing the reaction using $\mathrm{ZnO}$ nanoparticles. Compounds were obtained by reaction of 2-acetyl benzimidazole and indole-3-carbaldehyde $\mathbf{3 4}$ followed by Michael's addition of indoles (Scheme 15). The method provided an excellent yield of product in less reaction time using water [23]. 
<smiles>[R]c1ccc2nc(C(C)=O)[nH]c2c1</smiles>

4<smiles>O=Cc1c[nH]c2ccccc12</smiles>

34

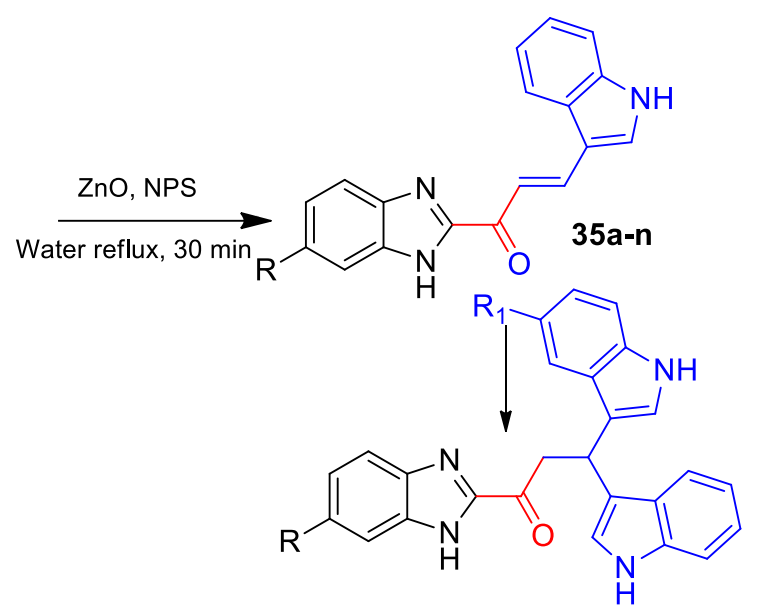

36a-n

$\mathrm{R}=\mathrm{H}, \mathrm{NO}_{2} \quad \mathrm{R}_{1}=\mathrm{H}, \mathrm{NO}_{2}, \mathrm{CH}_{3}, \mathrm{OCH}_{3}, \mathrm{~F}, \mathrm{Cl}, \mathrm{Br}$

Scheme 15. Synthesis of benzimidazole chalcones 36a-n.

Benzimidazole chalcones bearing heterocyclic moieties 39-41 were prepared from 2acetylbenzimidazole (Scheme 16). It was observed that benzimidazoles connected to 5 or 6 membered nitrogen-bearing rings showed cytotoxic effects on OVCAR-3 and MCF-7 cell lines. The compound 41 (containing morpholinopropyl group) reduced the proliferation of MCF-7 $\left(\mathrm{IC}_{50}=8.91 \mu \mathrm{M}\right)$ and OVCAR-3 $\left(\mathrm{IC}_{50}=10.76 \mu \mathrm{M}\right)$ cell lines and showed good activity compared to cisplatin [24].

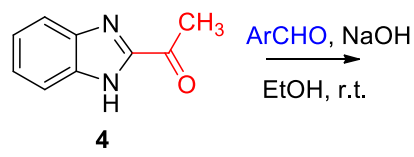

$a ; R_{1}=H, b ; R_{1}=C_{3}, c ; R_{1}=\mathrm{OCH}_{3}, d ; R_{1}=\mathrm{Cl}$
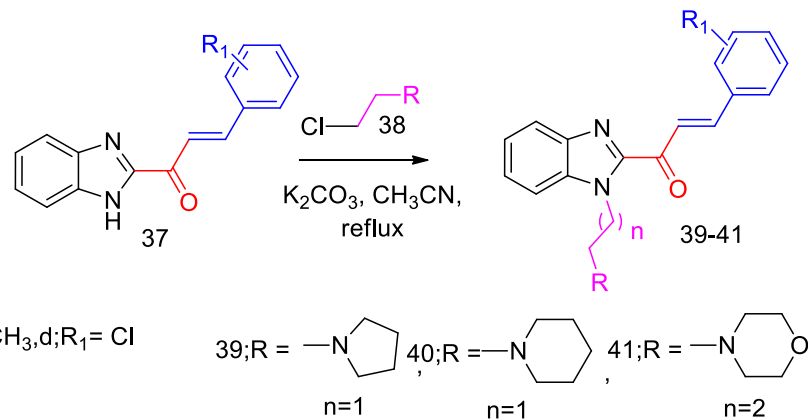

Scheme 16. Synthesis of benzimidazole chalcones 39-41.

3.2. Synthesis of the three-membered ring (oxirane and its derivatives).

Benzimidazole chalcone $\mathbf{4 3}$ was synthesized from 2-acetyl-1-methylbenzimidazole $\mathbf{4 2}$ and 3,4,5-Trimethoxybenzaldehyde. Treatment of $\mathbf{4 3}$ with $30 \%$ hydrogen peroxide in acetone yielded 44 (Scheme 17) [25].

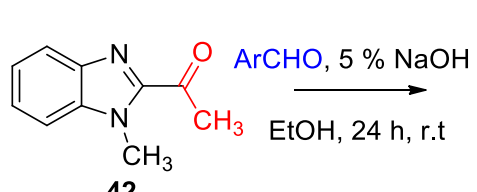

42

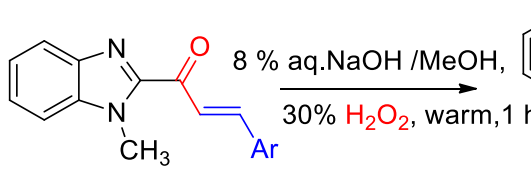

43

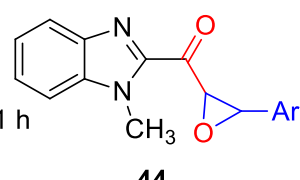

44

$\mathrm{Ar}=3,4,5-\mathrm{OCH}_{3} \mathrm{C}_{6} \mathrm{H}_{2}$

Scheme 17. Synthesis of benzimidazole oxirane 44.

\subsection{Synthesis of the five-membered rings.}

\subsubsection{Synthesis of pyrazolines.}

Two series of pyrazoline were prepared, starting from 2-acetyl benzimidazole. The cyclo condensation of chalcones $\mathbf{4 5 a - e}$ with hydrazine hydrate and phenylhydrazine yielded 
different pyrazoline derivatives 46a-e and 47a-e (Scheme 18). The compounds were screened against Mycobacterium tuberculosis. Compounds 45a and 45d were found to have MIC values of 1.25 and $1.53 \mu \mathrm{g} / \mathrm{mL}$, respectively. Compounds $47 \mathbf{c}$ and $47 \mathbf{e}$ showed MIC values of 2.69 and 2.75 , respectively [26].

A similar pyrazoline series was synthesized by Shaharyar and co-workers and screened at a single dose $\left(10^{-5} \mathrm{M}\right)$ against NCI 60 cell panel. Derivativecontaining 3,4-dimethoxyphenyl group at $5^{\text {th }}$ position of pyrazoline $47 \mathrm{e}$ was found to be the most active candidate [27].

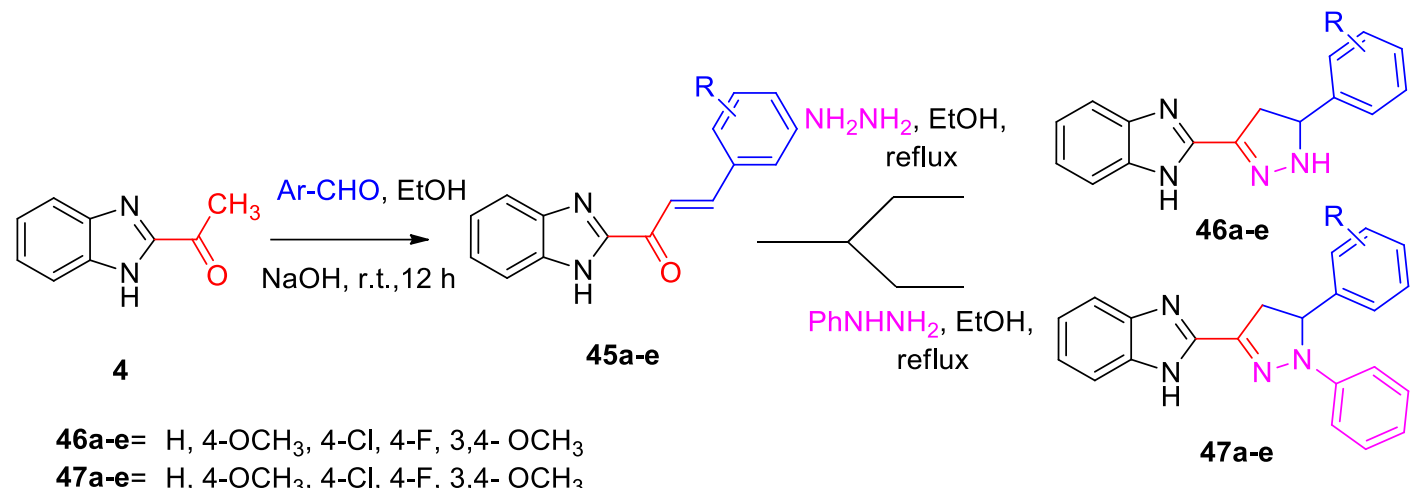

Scheme 18. Synthesis of benzimidazole pyrazolines 46a-e and 47a-e.

Series of pyrazolines 49a-b were synthesized from benzimidazolylchalcones $\mathbf{4 8 a - b}$ and phenylhydrazine to study their fluorescent properties (Scheme 19). The fluorescence spectra concluded that the emission wavelength was red-shifted. The absorption spectra revealed that the aryl group linked at the $5^{\text {th }}$ position of the pyrazoline ring barely influenced the maximum absorption [28].

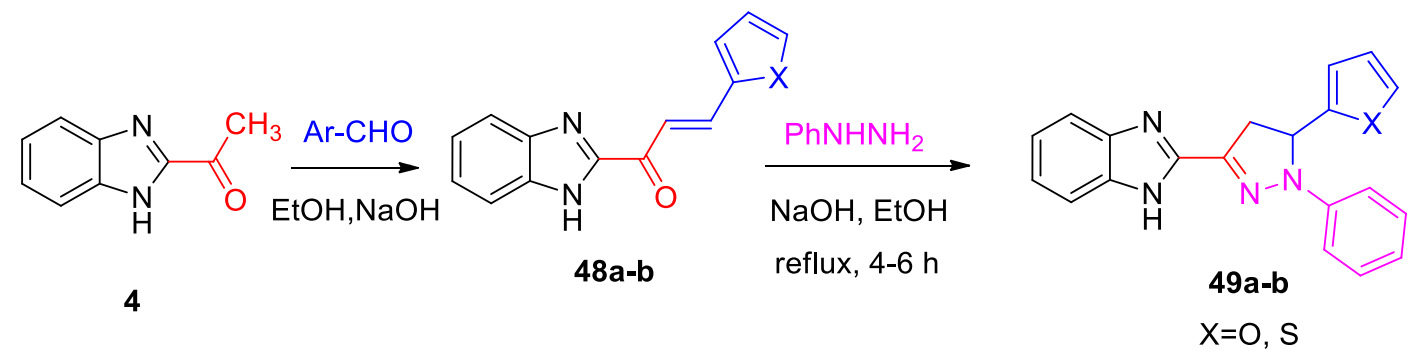

Scheme 19. Synthesis of benzimidazole pyrazolines 49a-b.

A series of benzimidazoles containing pyrazoline moiety 52a-j were synthesized by the cycloaddition of isoniazid $\mathbf{5 1}$ with benzimidazolylchalcones 50a-j (Scheme20). The synthesized compounds were evaluated for antimicrobial using the serial dilution technique. Compounds $\mathbf{5 2 b}, \mathbf{5 2 d}$, and $\mathbf{5 2 e}$ were found to be significantly active against different bacteria with MIC of $25 \mu \mathrm{g} / \mathrm{mL}$ [29].

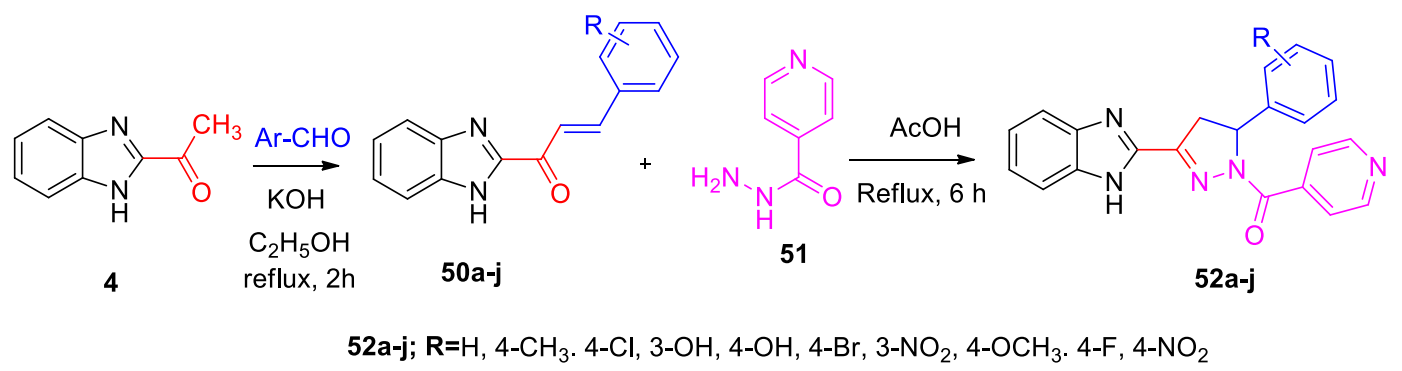

Scheme 20. Synthesis of benzimidazole pyrazolines 52a-j.

Benzimidazole linked pyrazoline 55a-j were achieved through the cyclo condensation of chalcone derivatives 53a-j with acid hydrazide 54 in acetic acid at $130^{\circ} \mathrm{C}$ (Scheme 21). 
Antimicrobial activity was determined against $S$. aureus, P. aeruginosa E. coli, A. niger, C. albicans, and A. clavatus. Few of the compounds were found to be significantly active [30].

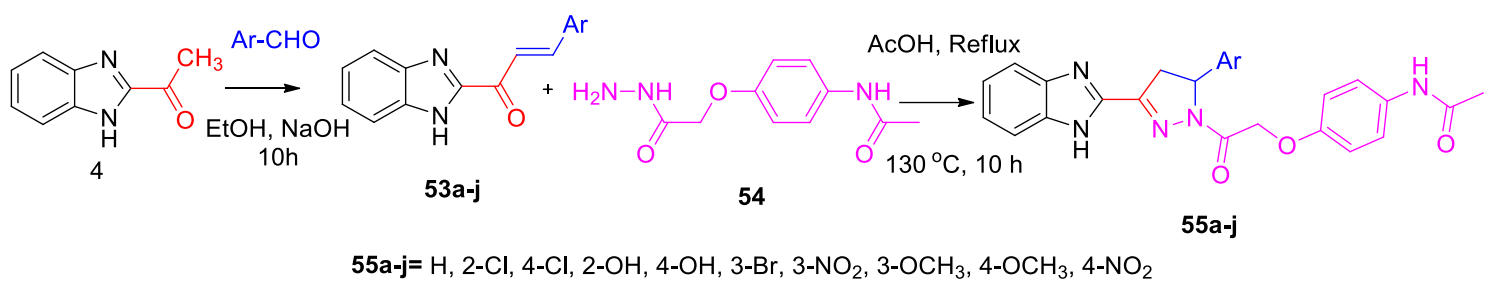

Scheme 21. Synthesis of benzimidazole pyrazolines 55a-j.

Benzimidazolylchalcones 56a-d have been cyclized into $\mathrm{N}^{1}$-substituted pyrazoline derivatives 57a-d and 58a-d by the interaction with thiosemicarbazide and formic acid under microwave condition (Scheme 22). Compounds synthesized were evaluated against B. Subtilis, $K$. pneumonae, E. coli, and P. aeruginosa. Few compounds showed unusual activity [31].

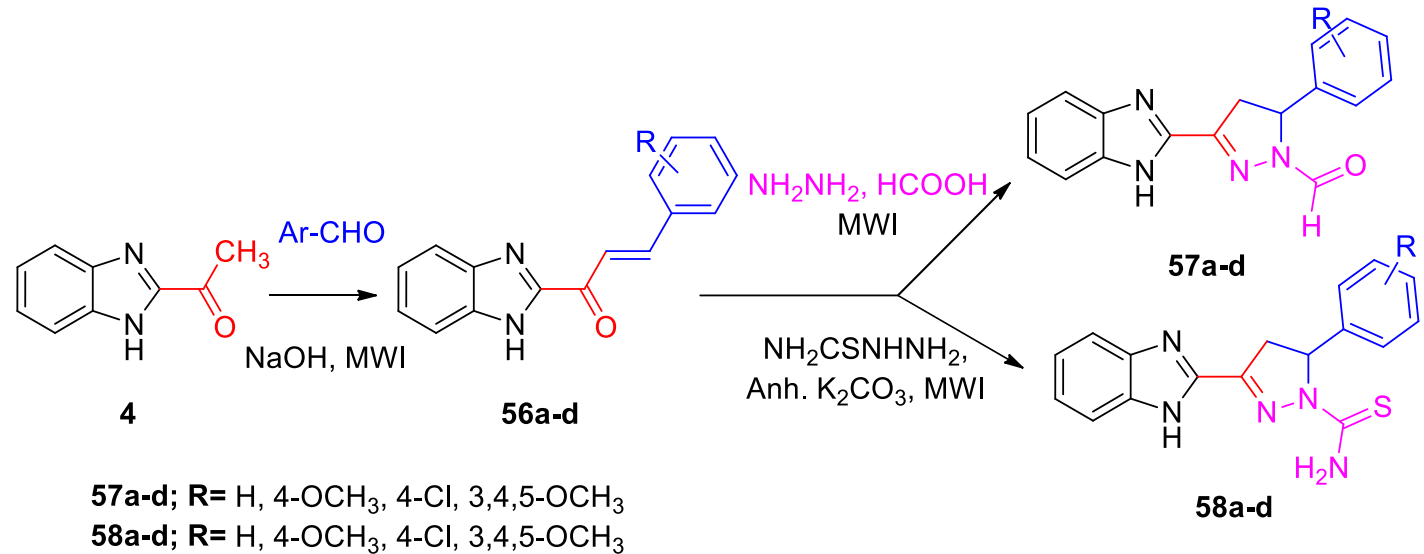

Scheme 22. Synthesis of benzimidazole pyrazolines 57a-d \& 58a-d.

Benzimidazolylchalcones 59a-f, obtained from 2-acetylbenzimidazole was reacted with hydrazine hydrate in the presence of formic acid to afford pyrazolinecarboxaldehyde $60 \mathrm{a}-$ f, which on reaction with hydrazine hydrate resulted in compounds 61a-f in 80-89\% yield under MWI condition (Scheme 23). Compounds were tested for their antifungal and antibacterial activity [32].

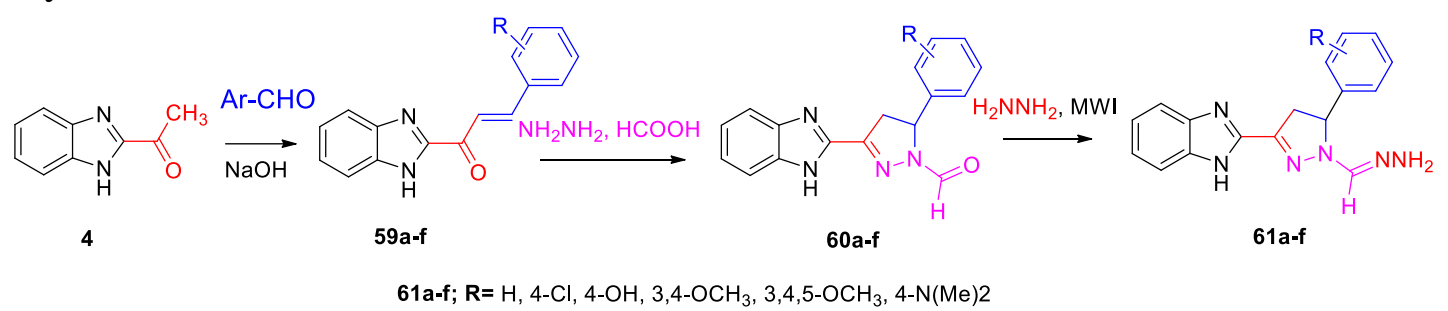

Scheme 23. Synthesis of benzimidazole pyrazolines 61a-f.

Two series of pyrazoline derivatives linked to benzimidazole moiety 64a-e and 65a-e were prepared in our laboratories by multistep reactions using 2-aceylimidazole as a starting material (Scheme 24). The compounds were tested for their antimicrobial activity. Among the compounds screened, $64 \mathrm{~d}$ showed good activity $\left(M I C=64 \mu \mathrm{gmL}^{-1}\right)$ against $S$. aureus and $E$. coli. Compounds were found to be inactive against $C$. albicans [33]. 


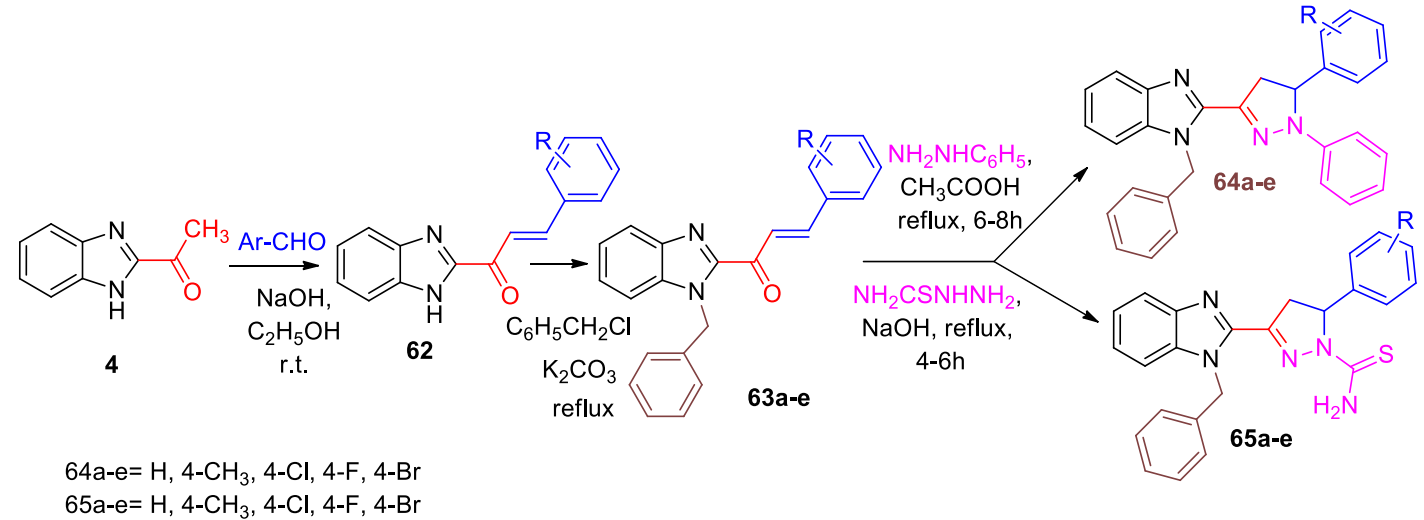

Scheme 24. Synthesis of benzimidazole pyrazolines 64a-e \& 65a-e.

A series of benzimidazole chalcones containing furan moiety $\mathbf{6 6} \mathbf{a}-\mathbf{b}$ were synthesized 67a-b from 2-acetylbenzimidazole. Chalcones were cyclized with methyl hydrazine in the presence of ethanol to produce pyrazolines (Scheme 25) [25].

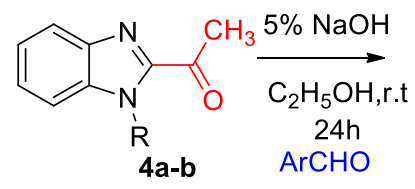

4a-b

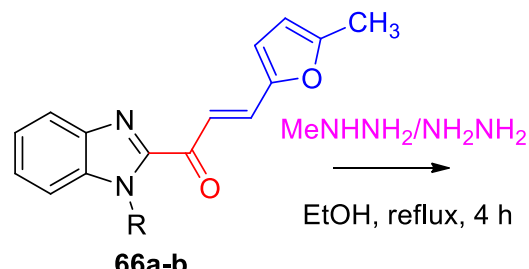

66a-b

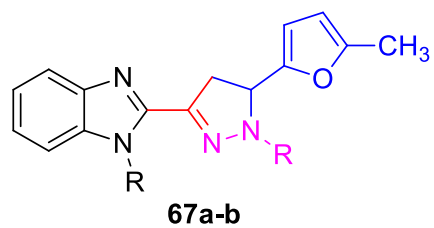

$\mathrm{R}=\mathrm{H}, \mathrm{Me}$

Scheme 25. Synthesis of benzimidazole pyrazolines 67a-b.

A series of benzimidazole and benzothiazole-linked pyrazolines 70a-e were prepared by reacting to the hydrazine 69 and chalcones $68 \mathrm{a}-\mathbf{e}$ using a small amount of glacial acetic acid in ethanol (Scheme 26). Compounds were screened for their anti-inflammatory \& analgesic activity and were found to be moderately active [34].

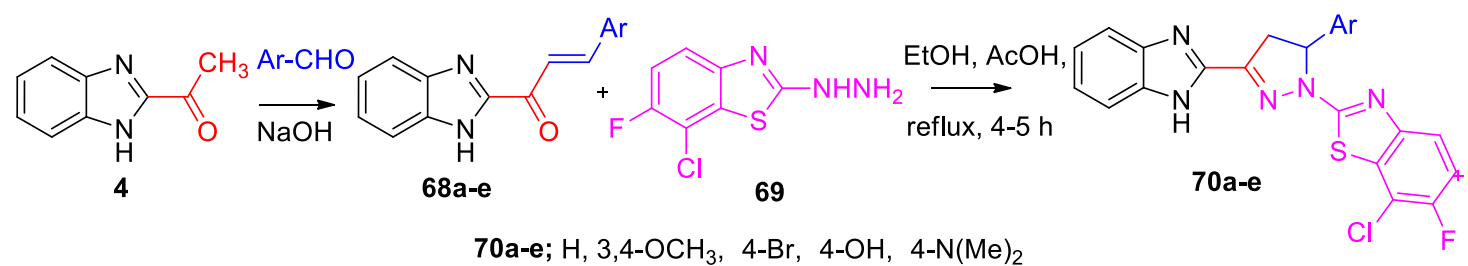

Scheme 26. Synthesis of benzimidazole pyrazolines 70a-e.

A series of benzimidazole chalcones bearing indole ring system 72a-c were prepared by Saundane et al. [35]. The chalcones 72a-c on treatment with hydrazine or phenylhydrazine gave 73a-d (Scheme 27). Compounds were evaluated for their antimicrobial and antioxidant activities. Few of the compounds showed good activity.

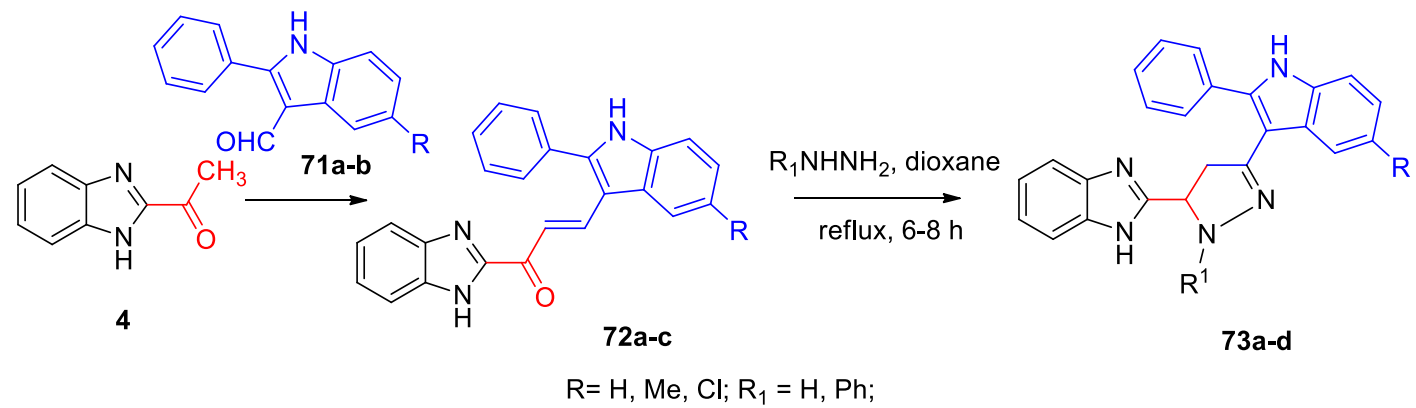

Scheme 27. Synthesis of benzimidazole pyrazolines 73a-d. 
Pyrazoline embedded with N-alkoxyphthalimidobenzimidazoles 76a-h were synthesized starting from 2-acetylbenzimidazole. The chalcones $\mathbf{7 4 a - d}$ were cyclized by refluxing with phenylhydrazine in the presence of pyridine. The pyrazolines 75a-d were condensed with $\omega$-bromoalkoxyphthalimide to obtain 76a-h (Scheme 28) [36].

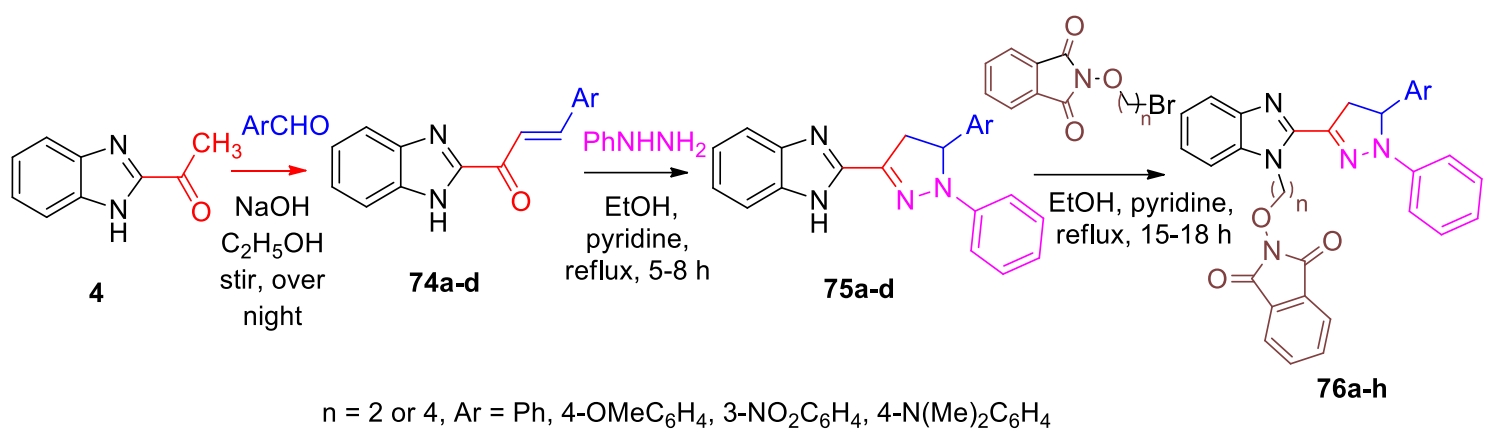

Scheme 28. Synthesis of benzimidazole pyrazolines 76a-h.

Compounds 2-(5-aryl-4,5-dihydropyrazol-3-yl)benzimidazoles 79a-d had been synthesized by the reaction of 3-aryl-1-(2-benzimidazolyl)-2-propen-1-ones 78a-d with hydrazine hydrate (Scheme 29) for evaluating them as potential anti-inflammatory agents. The compounds showed a good effect in the rat paw edema model [37].

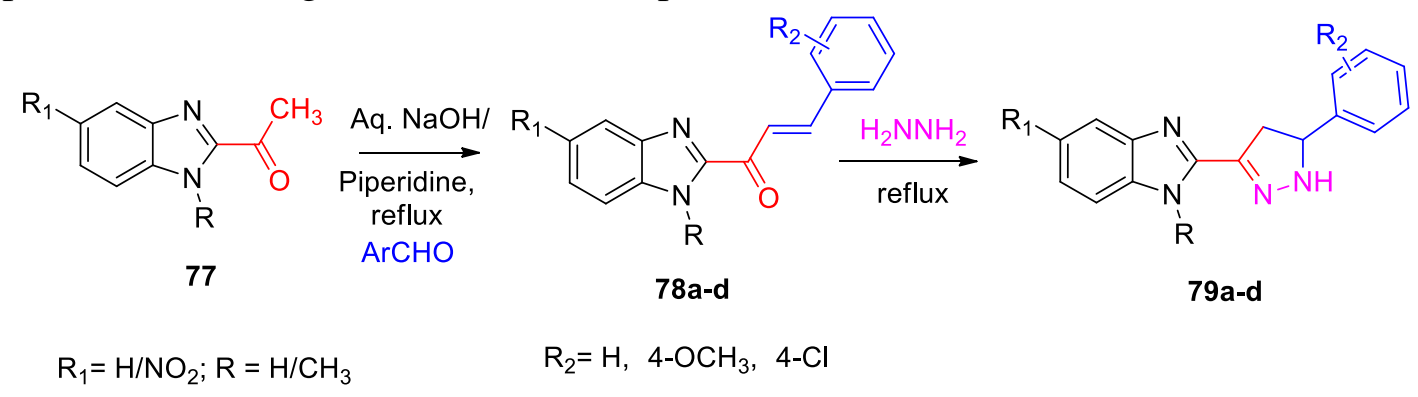

Scheme 29. Synthesis of benzimidazole pyrazolines 79a-d.

2-(4-amino-2-arylaminothiazol-5-oyl)-N-methylbenzimidazoles 82a-e were prepared to utilize 2-acetylbenzimidazole as a synthon (Scheme 30). The compounds were screened at a concentration of $10^{-4} \mathrm{M}$ against lung cancer (H460), breast cancer (MCF7), and SF268 (CNS cancer) cell lines. The compounds were further screened against different bacterial strains and found to be active [38].

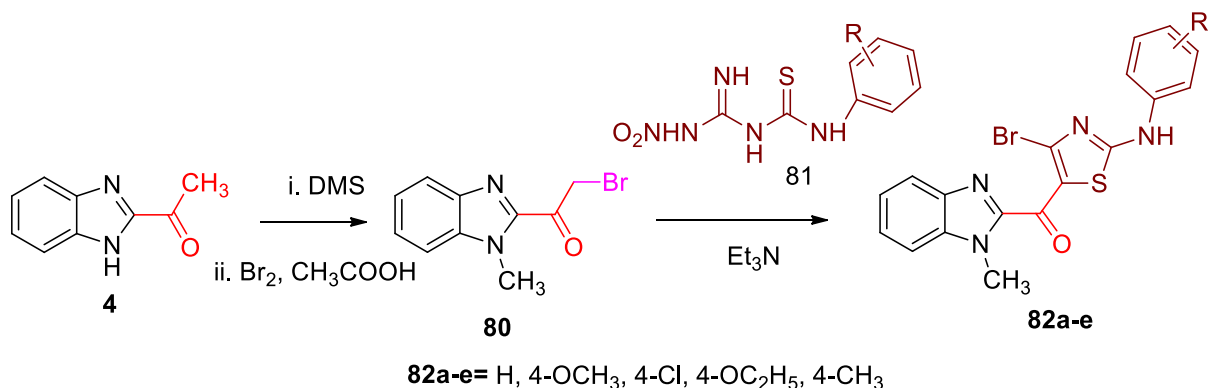

Scheme 30. Synthesis of benzimidazole pyrazolines 82a-e.

Two series of Thiazole-2-amines $84 a-d$ and $87 \mathbf{a}-\mathbf{i}$ has been prepared by the cyclization of 2-acetylbenzimidiazoles 83a-d \& 85a-i and 2-bromo-1-(1-alkyl-1H-benzo[ $[d]$ imidazol-2yl)-1-ethanone 86a-i with thiourea (Scheme 31) and evaluated for their antibacterial and antifungal activity. Some of these compounds demonstrated antibacterial activity [39]. 


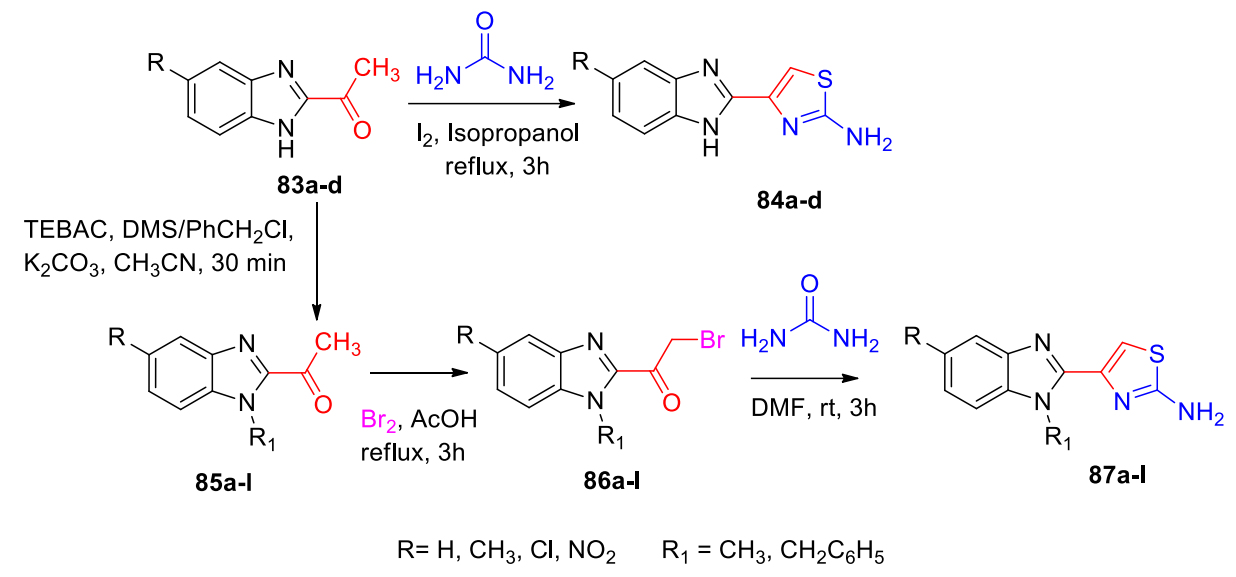

Scheme 31. Synthesis of benzimidazole linked thiazole-2-amines 87a-i.

A series of benzimidazoles linked with various heterocyclic systems 93, 94, 95, 97 and 98 have been synthesized from $N$-methyl-2-bromoacetylbenzimidazole 89 (Scheme 32). Some benzimidazole derivatives were found as corrosion inhibitors [40].

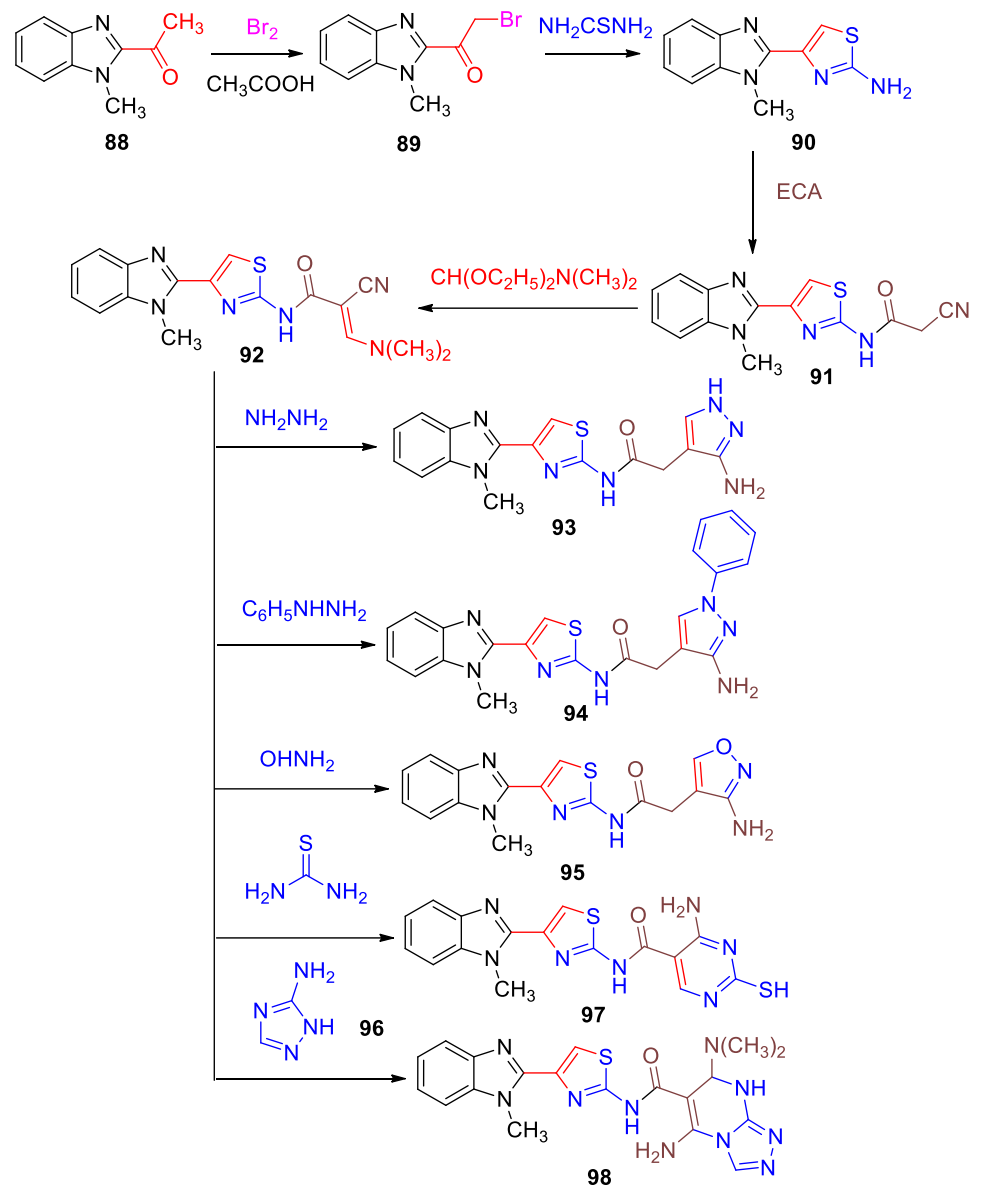

Scheme 32. Synthesis of benzimidazole linked heterocyclics 90-98.

\subsubsection{Synthesis of pyrazoles.}

The reaction of benzimidazolylchalcones 99a-e with bromine in chloroform gave corresponding dibromochalcones 100a-e, which underwent condensation with hydrazine hydrate to form 3-benzimidazolyl-5-aryl-2-pyrazole 101a-e (Scheme 33). Pyrazoles were evaluated for their antimicrobial activity, and some of them have exhibited promising activity [41]. 


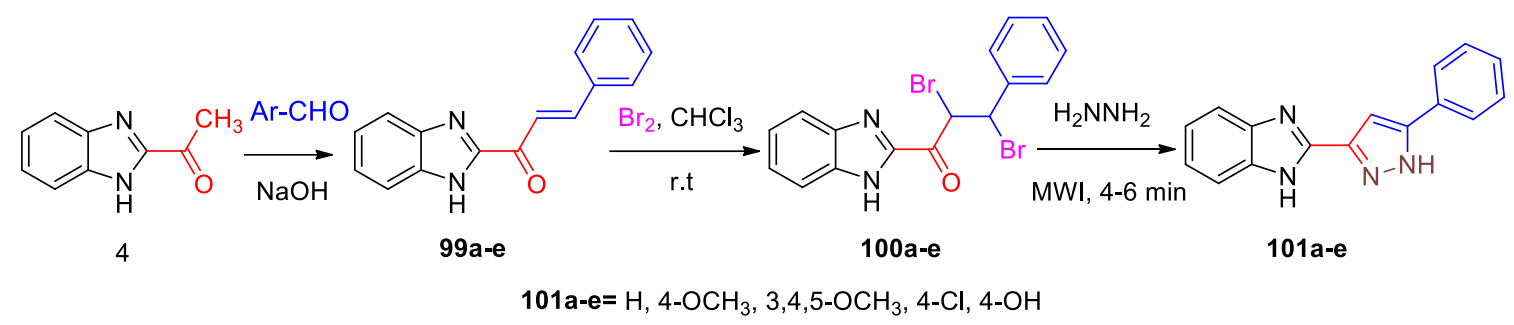

Scheme 33. Synthesis of benzimidazole linked pyrazole 101a-e.

2-acetylbenzimidazole on heating with dimethyl acetal in dimethylformamide gave the chalcone 1-(1H-benzimidazolyl)-3-dimethylaminopropenone 102. Alkylation of $\mathbf{1 0 2}$ with $\mathrm{DMS} / \mathrm{DES} / \mathrm{PhCH}_{2} \mathrm{Cl}$ gave 103a-c that the treatment of with hydrazine gave 104a-c (Scheme 34) $[42]$.

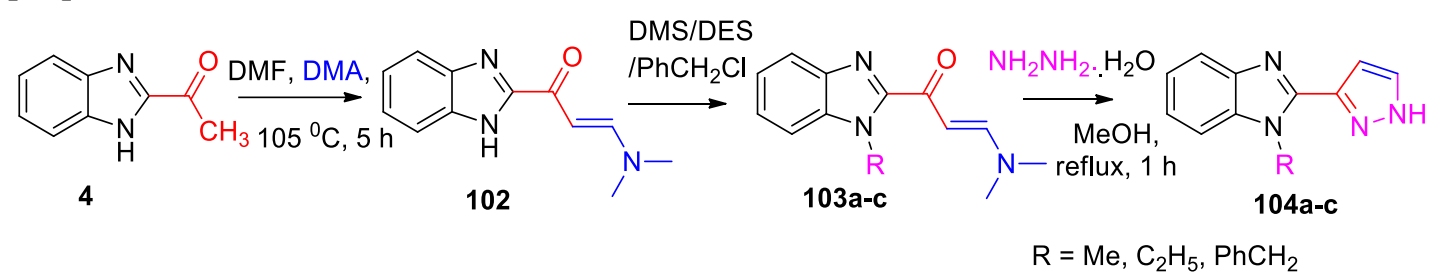

Scheme 34. Synthesis of benzimidazole linked pyrazole 104a-c.

The chalcones 105a-e were cyclized with phenylhydrazine, and 2,4-dinitro phenylhydrazine in the presence of sodium acetate under microwave irradiation to give the benzimidazole substituted pyrazole 106a-e (Scheme 35). Some of the compounds showed significant anti-cancer and antibacterial activity [10].

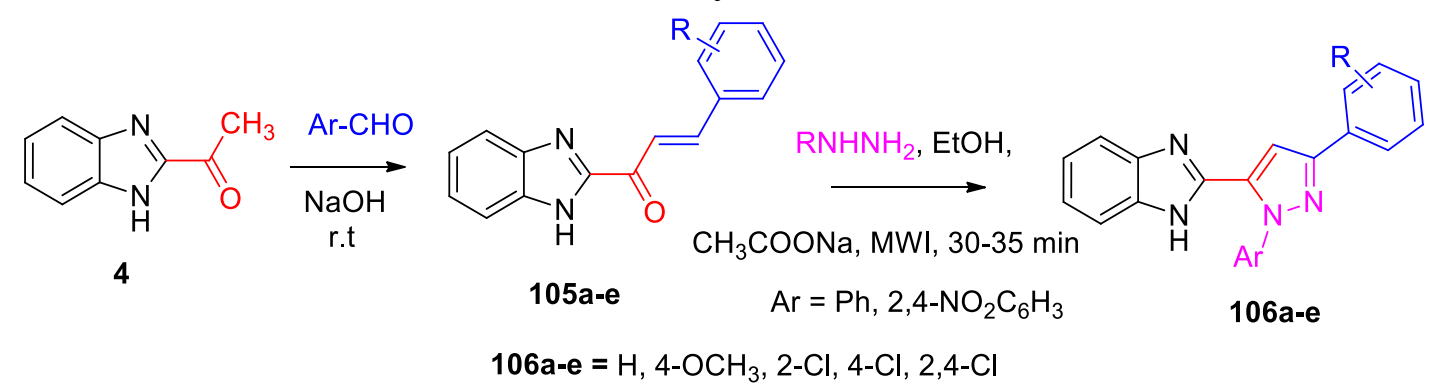

Scheme 35. Synthesis of benzimidazole linked pyrazole 106a-e.

The pyrazoles 108a-e derivatives were prepared from chalcones 107a-e (Scheme 36). The compounds were tested for anti-inflammatory activity and showed significant $\%$ inhibition of edema, i.e., 63.63, and $62 \%$ at a dose of $200 \mathrm{mg} / \mathrm{mL}$ [43].

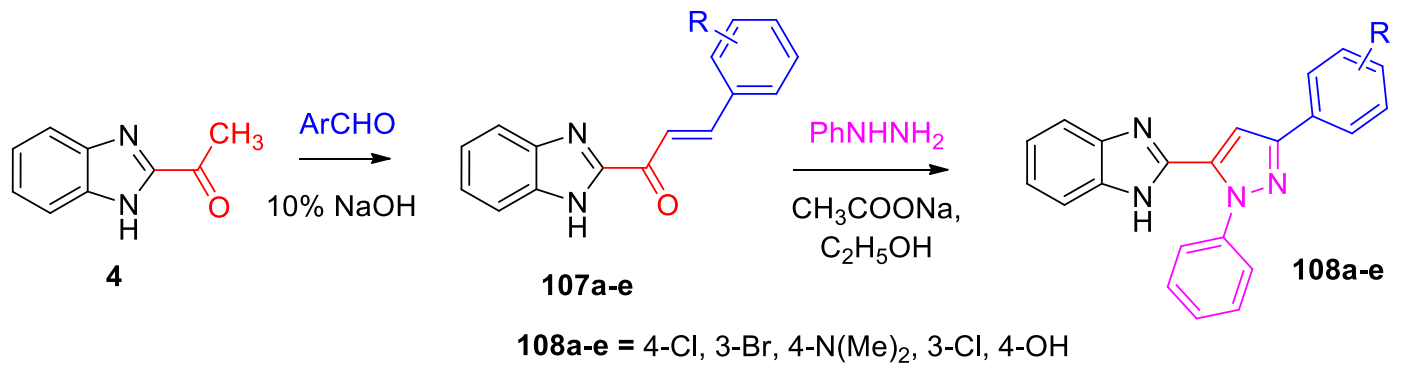

Scheme 36. Synthesis of benzimidazole linked pyrazole 108a-e.

\subsubsection{Synthesis of isoxazolines.}

The syntheses of Benzimidazole-arylisoxazoline hybrid 110a-h were obtained by the condensation of chalcones 109a-h with hydroxylamine at room temperature (Scheme 37). The 
compounds were tested for their antibacterial activity against Gram +ve bacteria viz., $B$. subtilis, S. aureus, and two Gram-ve bacteria viz. E. coli and K. pneumonia and found to be active [44].

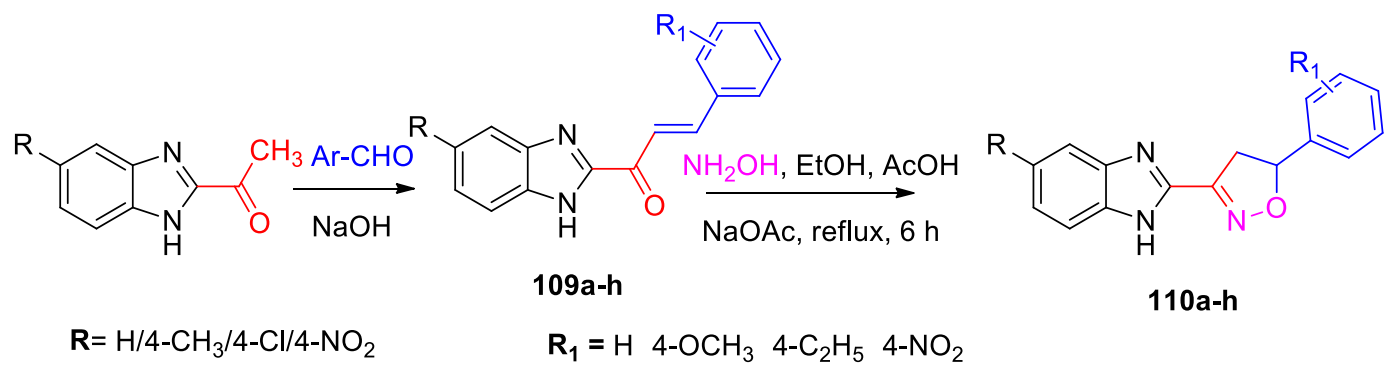

Scheme 37. Synthesis of benzimidazole linked oxazoline 110a-d.

A series of 1-methyl analogs of benzimidazole chalcones 111a-b was cyclized with hydroxylamine hydrochloride in the presence of $\mathrm{NaOH}$ to produce isoxazolines 112a-b (Scheme 38). The derivatives exhibited high potency against cancer cells HEPG2 and PC12cell lines [25].

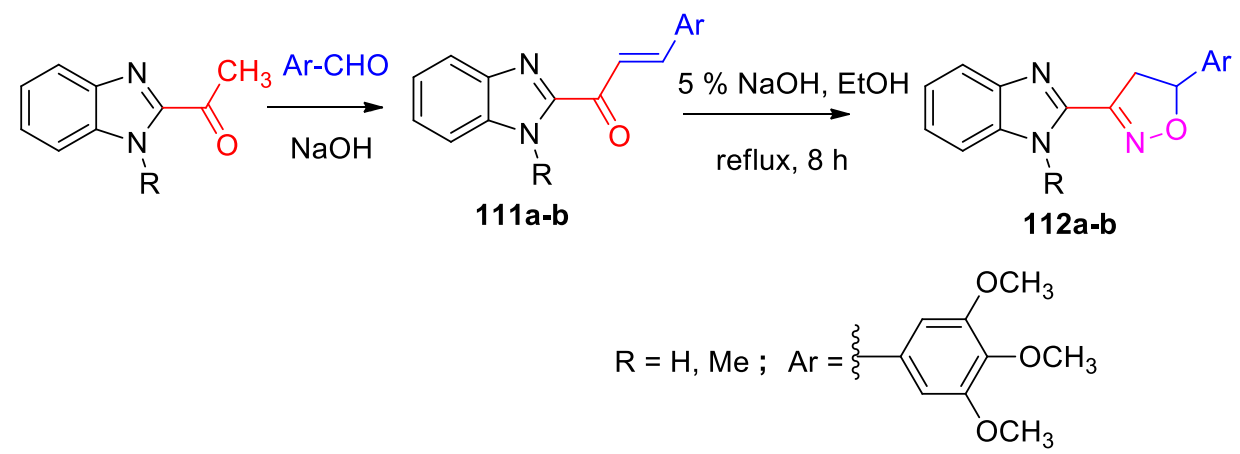

Scheme 38. Synthesis of benzimidazole linked oxazoline 112a-b.

The chalcone 113 was cyclized with hydroxylamine hydrochloride using a catalytic amount of sodium acetate in a mixture of acetic acid and ethanol under reflux conditions. The isoxazoline 114 so obtained were condensed with $\omega$-bromoalkoxy-phthalimide $\mathbf{1 1 5}$ in a mixture of pyridine and ethanol to obtain 2-(5-aryl-4,5-dihydroisoxazol-3-yl)-1-Nalkoxyphthalimido benzimidazoles 116a-h (Scheme 39) [36].

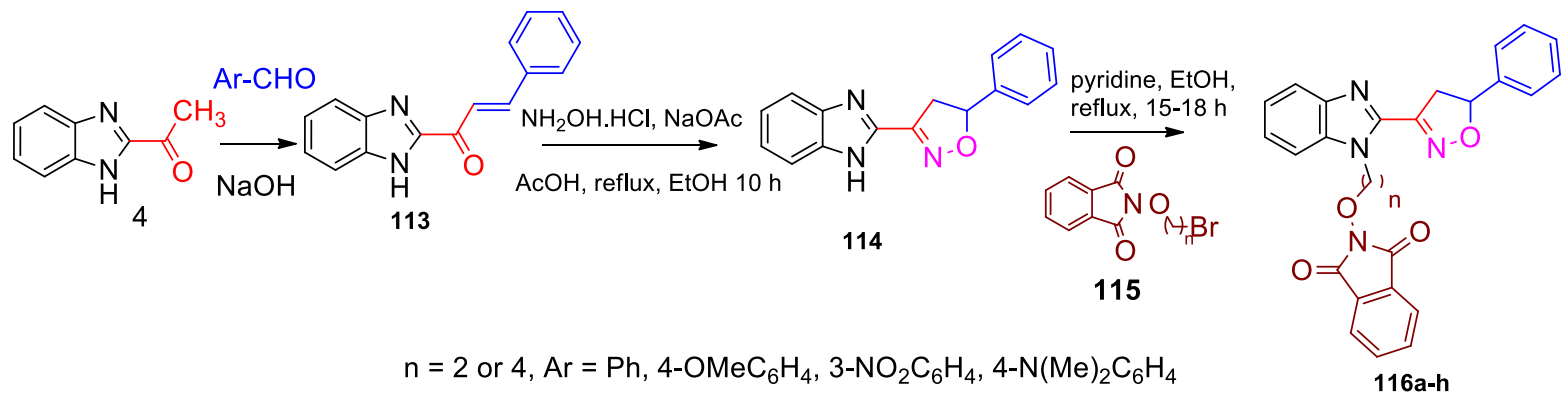

Scheme 39. Synthesis of benzimidazole linked oxazoline 116a-h.

\subsubsection{Synthesis of isoxazoles.}

2-Acetylbenzimidazole on condensation with different aldehydes produced 3(benzimidazole-2-yl)-1-aryl-1-propen-3-ones 117a-g. Chalcones on condensation with hydroxylamine hydrochloride in the presence of sodium acetate using a minimum amount of acetic acid produced 3-(benzimidazole-2-yl)-5-arylisoxazoles 118a-g (Scheme 40). The 
compounds were evaluated for their anti-cancer activity against MCF-7 and NCI-H460 cell line [45].

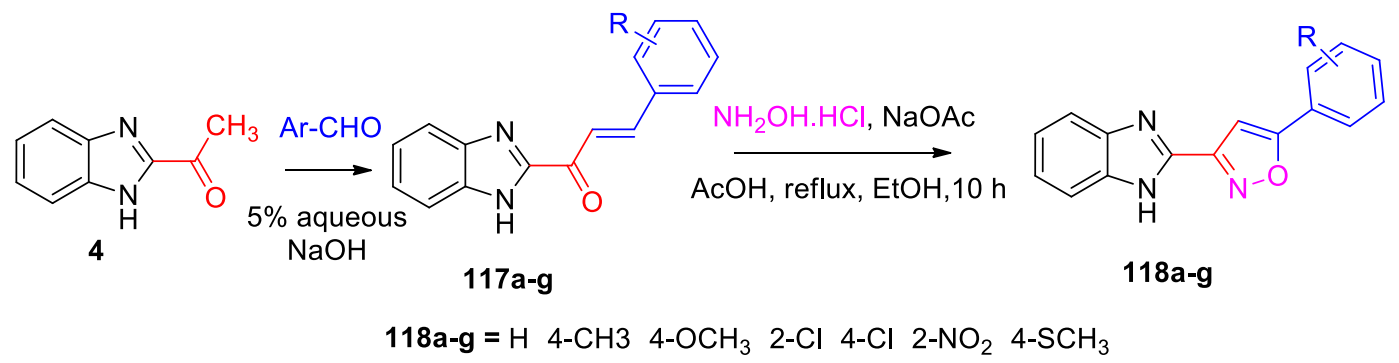

Scheme 40. Synthesis of benzimidazole linked oxazole 118a-g.

\subsection{Synthesis of the six-membered rings.}

\subsubsection{Synthesis of pyridine and its derivative.}

Benzimidazole embedded pyridine derivatives 121a-f were synthesized (Scheme 41) by reacting chalcones 119a-f with malononitrile $120 \&$ ammonium acetate. Obtained compounds were evaluated for their antibacterial and antifungal activity. The compounds showed good antibacterial and moderate antifungal activities [46].

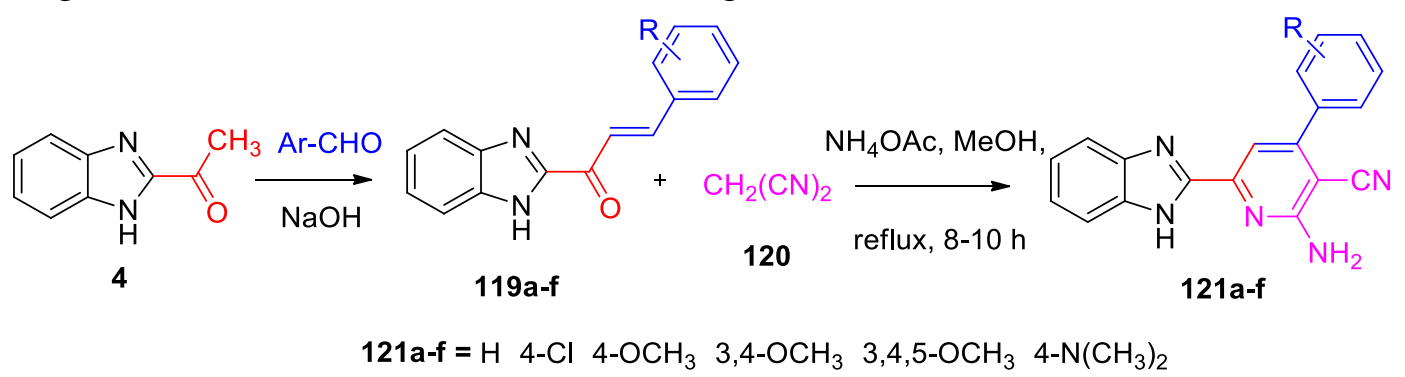

Scheme 41. Synthesis of benzimidazole linked pyridine 121a-f.

A series of benzimidazole derivatives 124a-f were synthesized (Scheme 42) by reacting compound 123a-f with formamide and formic acid in dimethylformamide solvent. Compounds 123a-f were prepared by reaction between benzimidazole chalcone 122a-f, malononitrile, and ammonium acetate in the ethanol medium. Compounds were screened for their antioxidant and antibacterial activity through DPPH and agar diffusion methods. The compounds demonstrated mild to moderate activity [47].

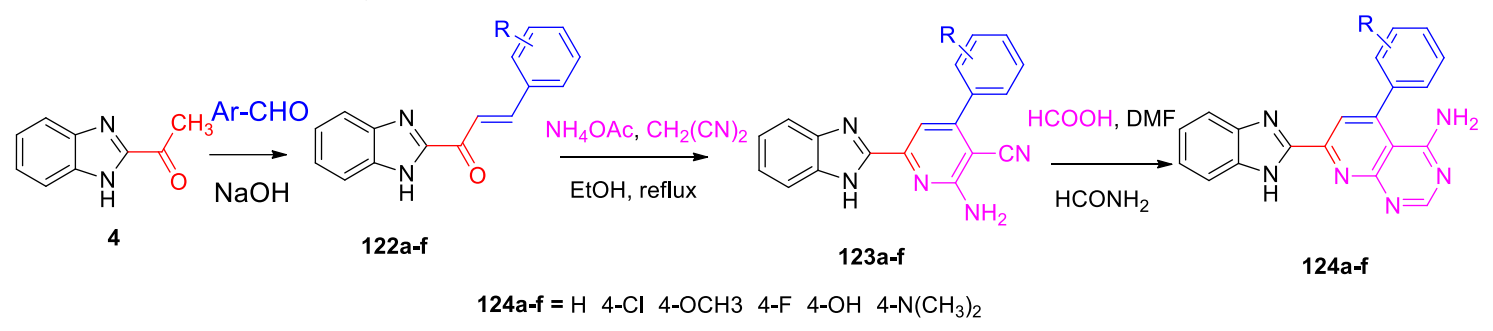

Scheme 42. Synthesis of benzimidazole linked pyridopyrimidine 124a-f.

Compounds 125a-f were treated with malononitrile and ammonium acetate to achieve derivatives 126a-f, via Knoevenagel condensation reaction. Compounds 126a-f on simple condensation reaction with 3-nitrobenzaldehyde provided Schiff bases 127a-f that in anhydrous 1,4-dioxane was refluxed with 2-mercaptoacetic acid 128 for $12 \mathrm{hrs}$ to obtain 129af (Scheme 43). These compounds were tested for antibacterial, antifungal, and cytotoxic activity [48]. 


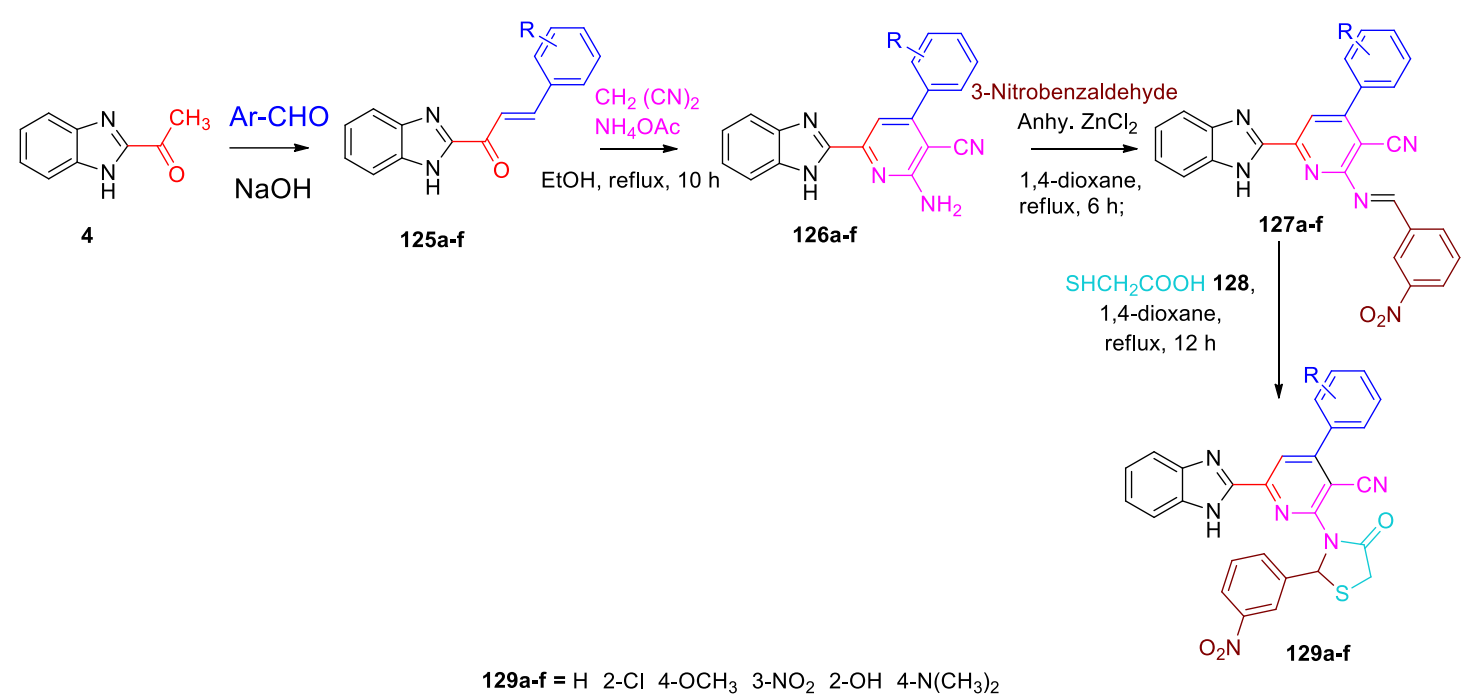

Scheme 43. Synthesis of benzimidazole linked pyridine 129a-f.

Desai et al. [49] prepared benzimidazole-pyridine-azetidine hybrid 133a-h (Scheme 44), stating from 2-acetyl benzimidazole through chalcone intermediates 130a-h. Chalcone derivatives were condensed with malononitrile in the presence of ammonium acetate to afforded 131a-h, which on reaction with benzaldehyde in the presence of anhydrous zinc chloride resulted in 132a-h. Compound 132a-h and chloroacetyl chloride were refluxed with triethylamine in 1,4-dioxane to obtain 133a-h. The compounds were screened for their antibacterial activity and exhibited substantial antibacterial activity accompanied by a low level of cytotoxicity against HeLa cells.
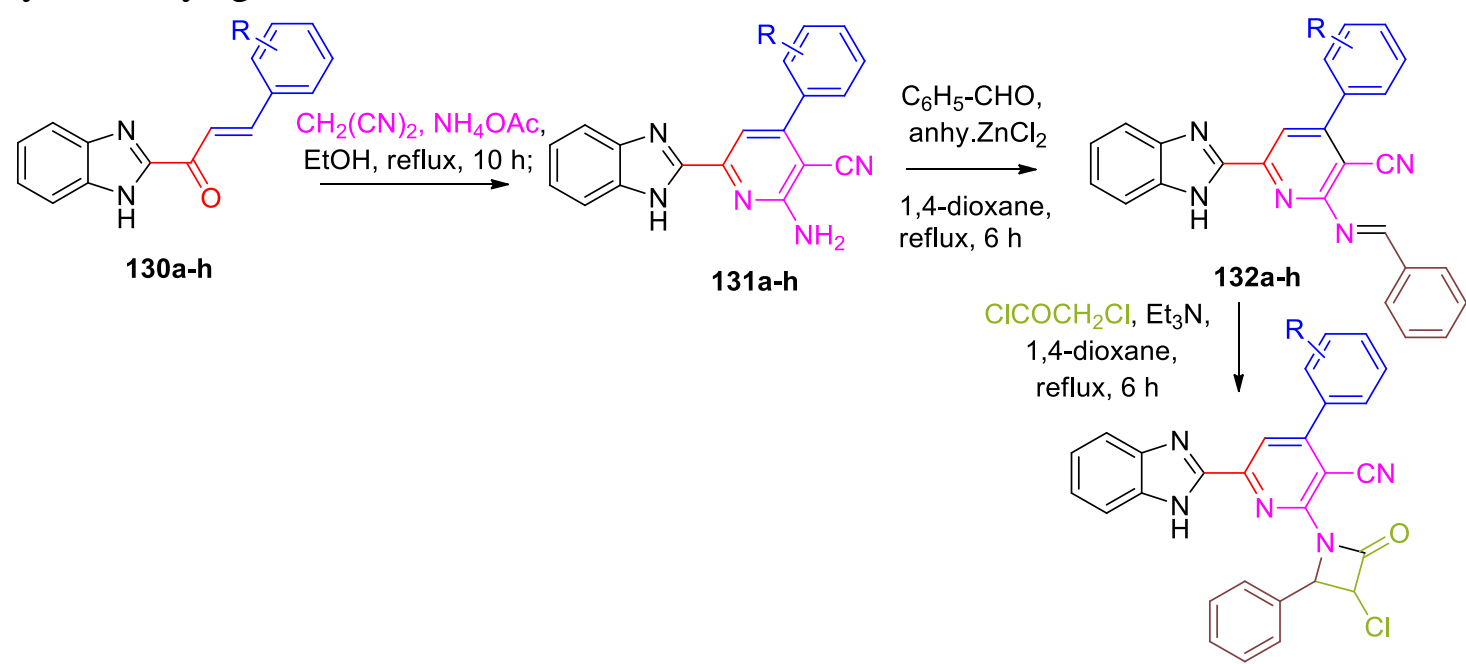

133a-h $=\mathrm{H} \quad 2-\mathrm{Cl} 3-\mathrm{Cl} 4-\mathrm{Cl} 2-\mathrm{OH} 3-\mathrm{OH} 4-\mathrm{OCH}_{3} 3-\mathrm{NO}_{2}$

133a-h

Scheme 44. Synthesis of benzimidazole linked pyridine 133a-h.

Benzimidazole-pyridines 135a-b were prepared (Scheme 45) by refluxing 2acetylbenzimidazole with suitable aromatic aldehydes $\mathbf{1 3 4 a - b}$, ethyl cyanoacetate, and ammonium acetate. The Compounds showed weak anti-HIV activity and had mild antibacterial activity. However, no significant anti-cancer activity was observed [50]. 


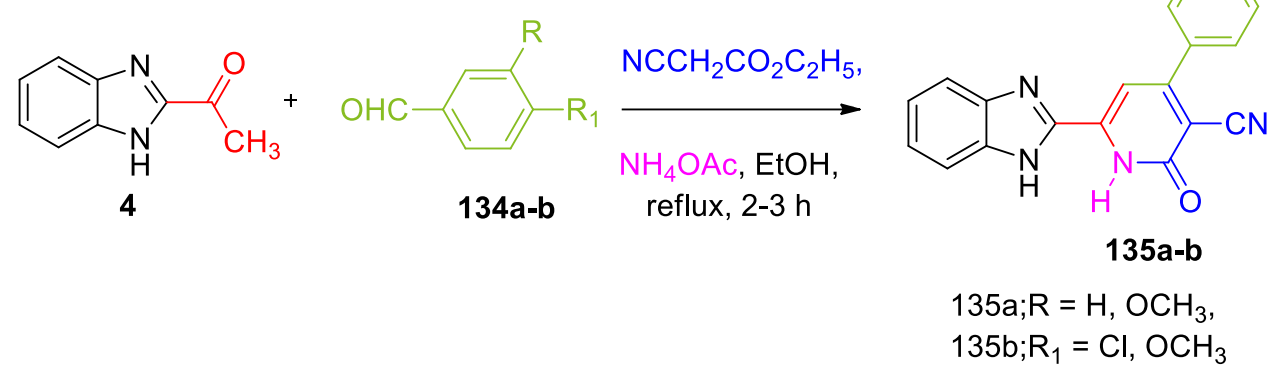

Scheme 45. Synthesis of benzimidazole linked pyridine $\mathbf{1 3 5 a - b .}$

A variety of benzimidazole-pyridine carbonitriles 137a-g were prepared (Scheme 46) via regioselective reaction of $\mathbf{1 3 6 a - g}$ with malononitrile in the presence of sodium alkoxide. All the synthesized compounds showed significant vasodilation properties [51].

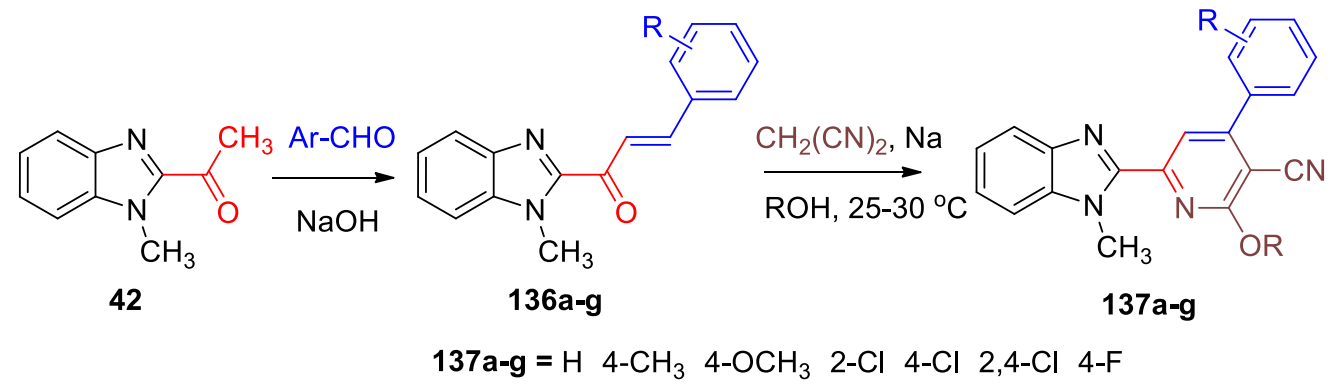

Scheme 46. Synthesis of benzimidazole linked pyridine 137a-g.

1- $\alpha$-Pyridiniumacetophenone chloride 139 on reaction with 2-cinnamoylbenzimidazole 138a-d in the presence of ammonium acetate gave pyridine derivatives 140a-d according to Kröhnke's pyridine synthesis (Scheme 47) [52].

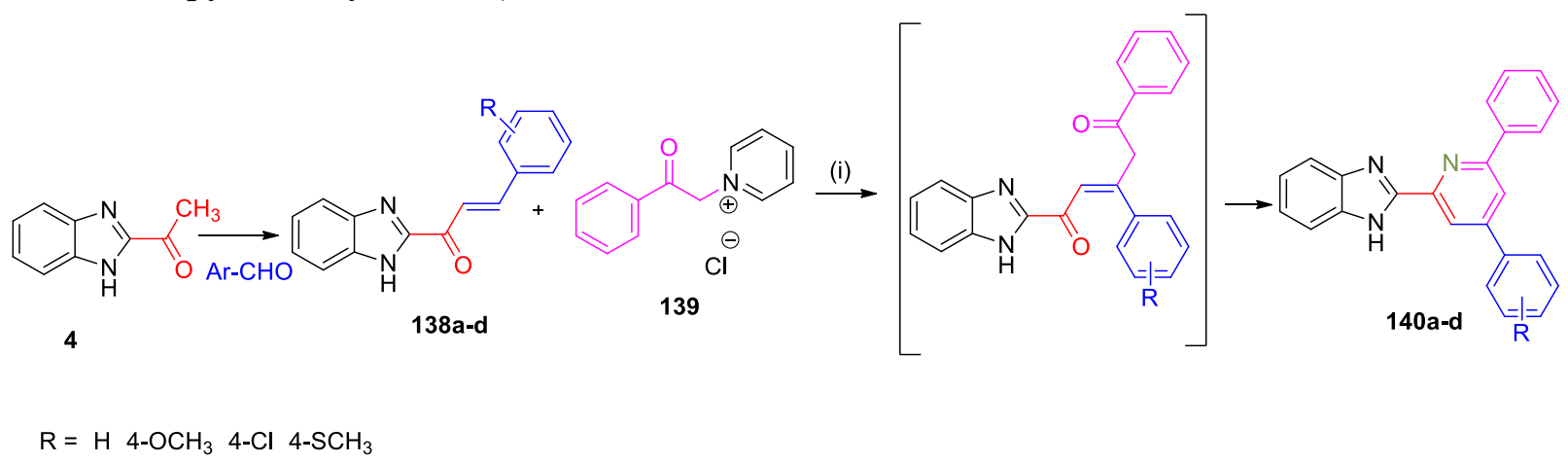

Scheme 47. Synthesis of benzimidazole linked pyridine 140a-d.

\subsubsection{Synthesis of pyrimidines.}

Zoorob et al. [53] have prepared various pyrimidine derivatives 142a-e \& 143a-e from the chalcones 141a-e (Scheme 48). Chalcones were reacted with thiourea in boiling alcoholic potassium hydroxide to give the pyrimidinethiones 142a-e. The analogous pyrimidines 143ae were prepared by the reaction of 141a-e with urea. 


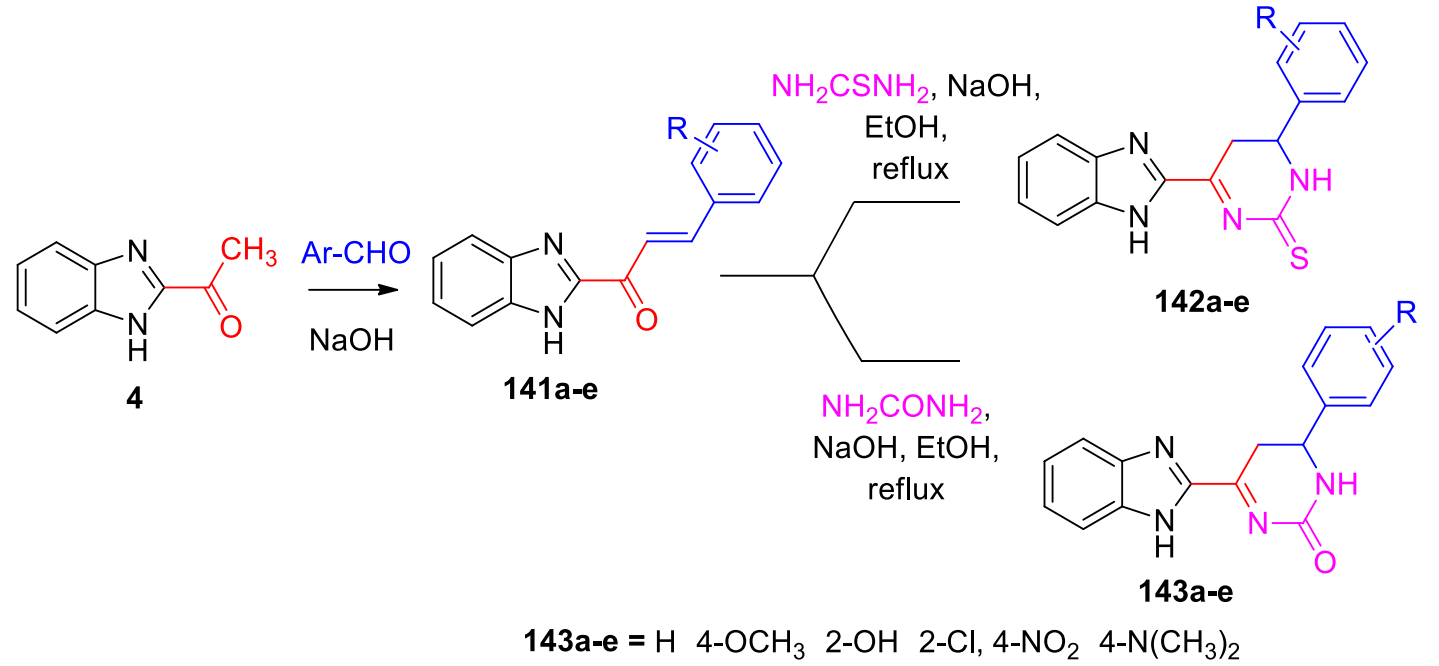

Scheme 48. Synthesis of benzimidazole linked pyrimidine 142a-e \& 143a-e.

A series of benzimidazole chalcone and its 1-methyl analogs 144a-d were cyclized (Scheme 49) with different reagents such as thiourea guanidinium sulfate in different reactions to produce pyrimidinethione 145a-d and aminopyrimidine 146a-d, respectively [51].

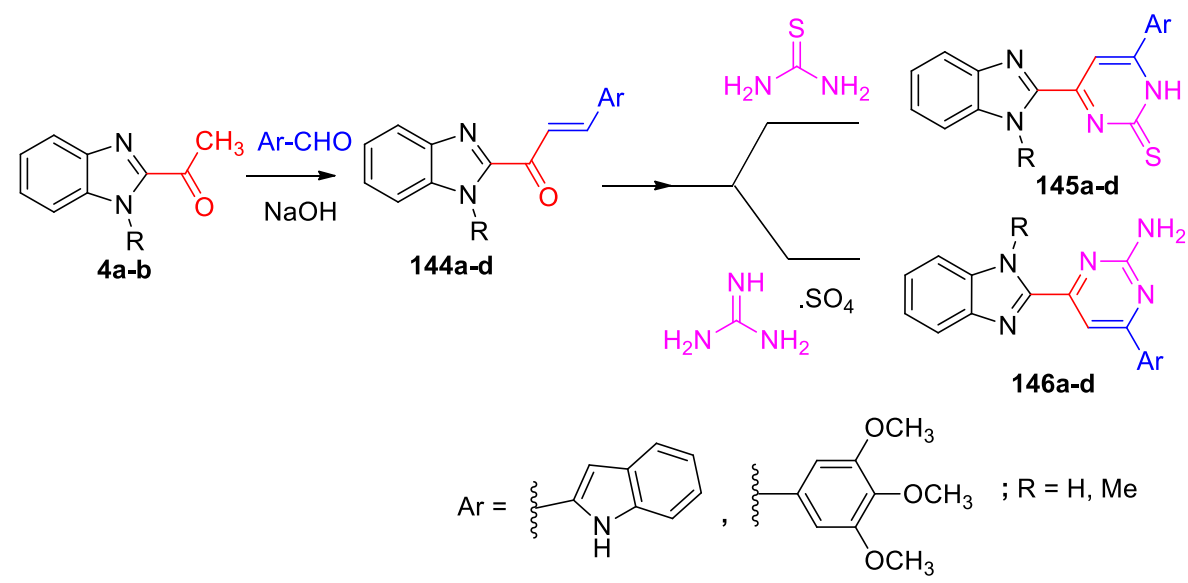

Scheme 49. Synthesis of benzimidazole linked pyrimidine 145a-d \& 146a-d.

The chalcones 72a-b on condensation with thiourea and urea in separate reactions yielded pyrimidine-2-thiol derivatives 147a-b and pyrimidin-2-ol derivatives 148a-b (Scheme 50), respectively. These compounds were screened for their antioxidant and antimicrobial activities and were found to possess good antioxidant and antimicrobial activity [35].

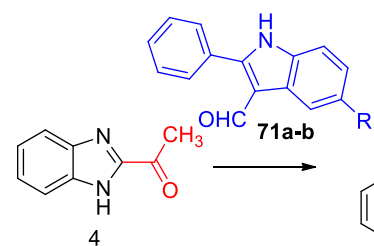

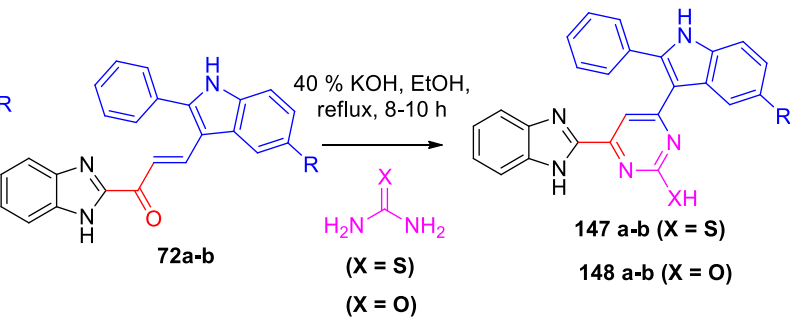

$\mathrm{R}=\mathrm{H}, \mathrm{Me}, \mathrm{Cl} ; \mathrm{R}_{1}=\mathrm{H}, \mathrm{Ph}$;

Scheme 50. Synthesis of benzimidazole linked pyrimidine $147 \mathbf{a}-\mathbf{b} \& \mathbf{1 4 8 a - b}$.

A series of 2-(2-amino-6-arylpyrimidin-4-yl)benzimidazoles 151a-d have been synthesized (Scheme 51) by the reaction of 3-aryl-1-(2-benzimidazolyl)-2-propen-1-ones 150a-d with guanidine carbonate. The compounds were found to be active as antibacterial [54]. 


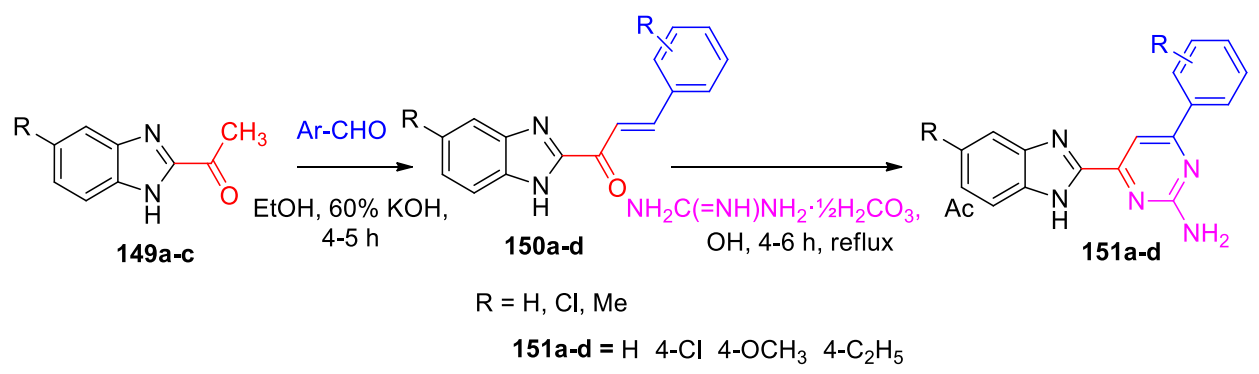

Scheme 51. Synthesis of benzimidazole linked pyrimidine 151a-d.

Two series of aminopyrimidinylbenzimidazoles 153a-d and 155a-p were synthesized as antibacterial agents (Scheme 52). Compound 153d significantly inhibited the growth of $E$. coli, A. flavus, and MRSA with MIC values of 1,1 , and $8 \mu \mathrm{g} / \mathrm{mL}$, respectively. 153d also exhibited bactericidal action against $S$. aureus MRSA and $P$. aeruginosa. Furthermore, compound 153d was found to show a good safety profile. A docking study concluded that $\mathbf{1 5 3 d}$ could bind with DNA gyrase [55].

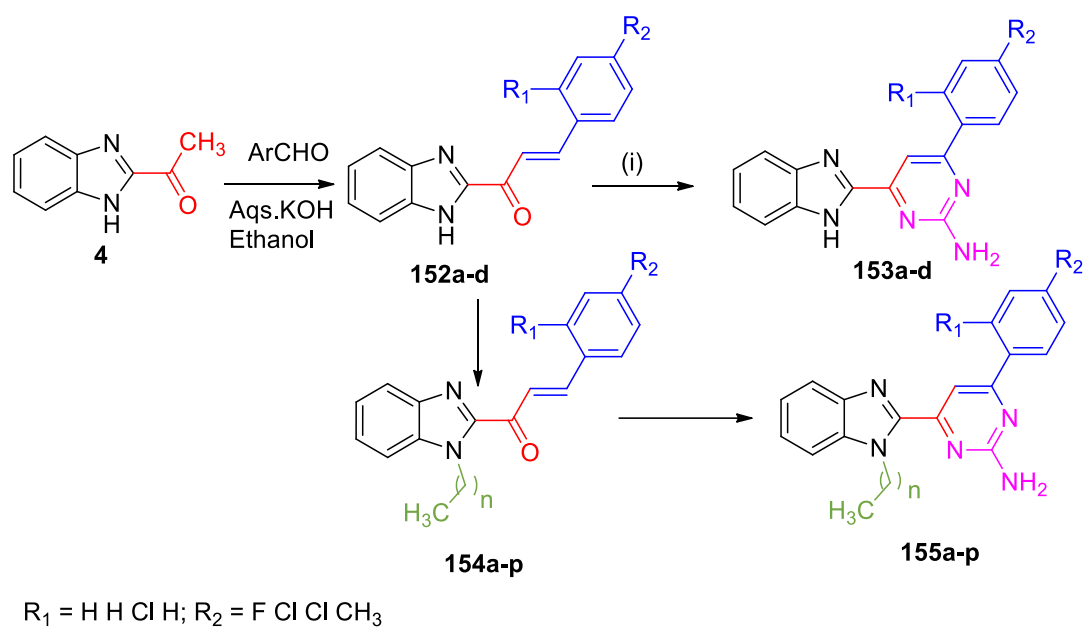

Scheme 52. Synthesis of benzimidazole linked pyrimidine 153a-p, 154a-p \& 155a-p.

N-benzyl benzimidazole-pyrimidine hybrid 158a-d were synthesized by the reaction of $\mathrm{N}$ benzyl benzimidazole chalcones 157a-d with guanidine hydrochloride (Scheme 53). Compounds 158a and $\mathbf{1 5 8 b}$ exhibited significant anti-cancer activity with GI50 values of 39.6 and $84.0 \mu \mathrm{M}[56]$.

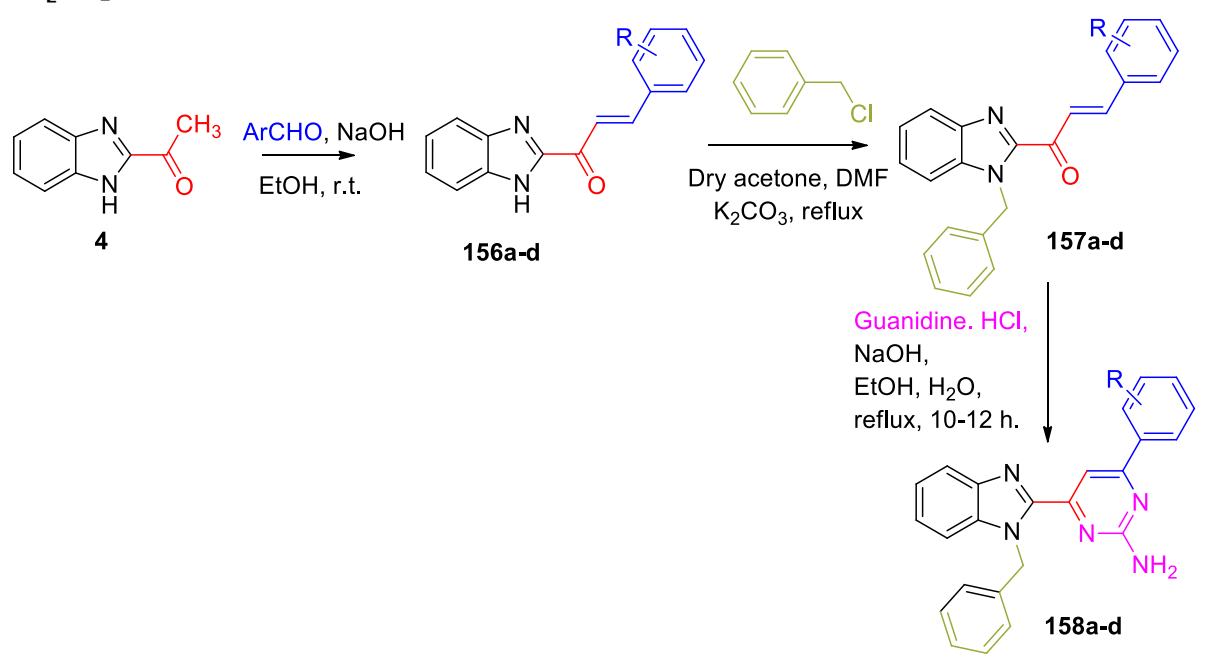

158a-d = $\mathrm{H}$ 4-CH3 4-Cl 4-Br 4-F

Scheme 53. Synthesis of benzimidazole linked pyrimidine 158a-d. 
A new series of pyrimidines 162a-j have been synthesized by the reaction of chalcone derivatives 161a-j with guanidine nitrate in ethanol and an aqueous solution of sodium hydroxide (Scheme 54) for testing their antimicrobial activity. Results reveal that compounds exhibited significant antibacterial and antifungal activities [57].

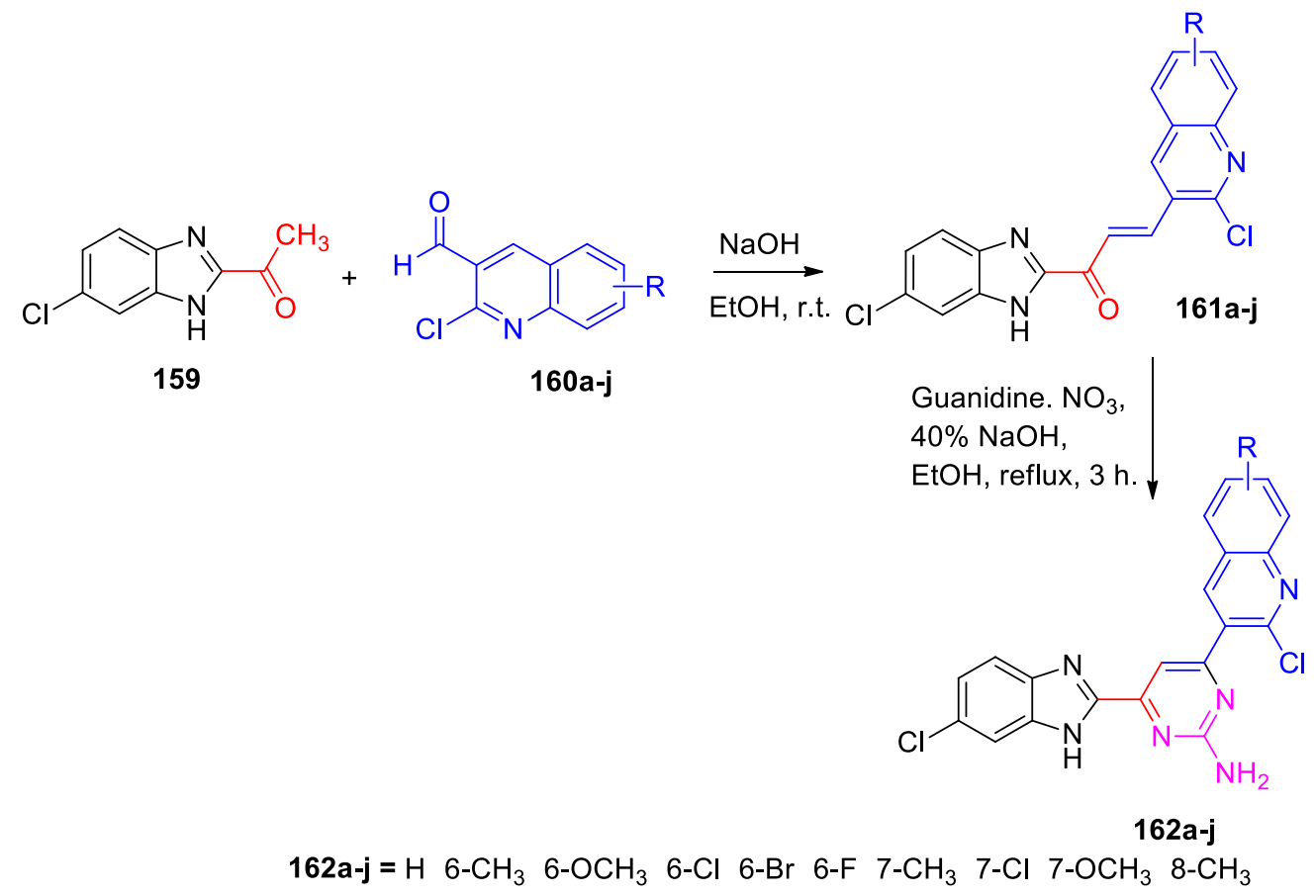

Scheme 54. Synthesis of benzimidazole linked pyrimidine 162a-j.

Benzimidazole-pyrimidine hybrid 163a-d were synthesized from chalcone precursors 74ad. The chalcones were cyclized with guanidine nitrate in the presence of $10 \% \mathrm{NaOH}$ under the reflux condition. The pyrimidines 163a-d were then condensed with $\omega$ bromoalkoxyphthalimide to obtain 164a-d (Scheme 55) [36].

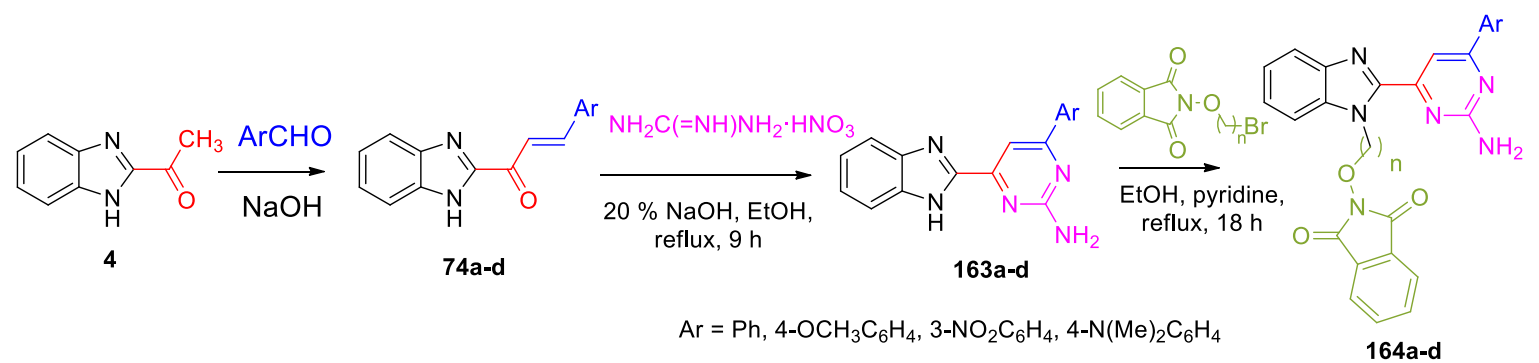

Scheme 55. Synthesis of benzimidazole linked pyrimidine 164a-d.

A series of benzimidazole-pyrimidine 163a-d have been synthesized (Scheme 56) by the reaction of chalcones 74a-d with guanidine carbonate for evaluating them as potential antiinflammatory agents. Compounds showed good anti-inflammatory activity in the carrageenaninduced rat paw edema model [37].

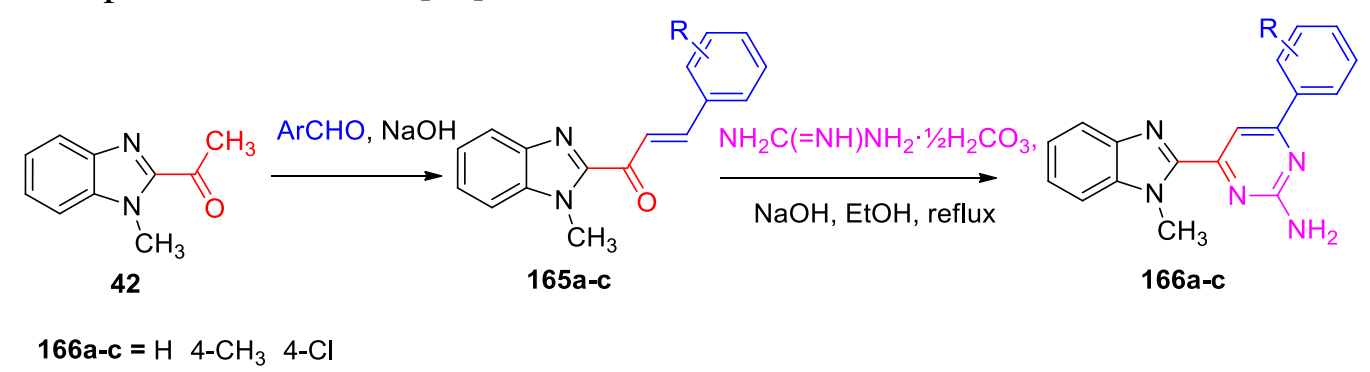

Scheme 56. Synthesis of benzimidazole linked pyrimidine 166a-c. 


\subsubsection{Synthesis of thiazines.}

Substituted 2-acetyl benzimidazole 167 irradiated with various aromatic aldehydes in an aqueous solution of $\mathrm{NaOH}$ and ethanol to obtain the chalcones 168. Chalcones 168a-e and thiourea were refluxed for $12-18$ hours at $60^{\circ} \mathrm{C}$ to obtain the thiazine derivatives $169 \mathrm{a}-\mathbf{e}$ (Scheme 57) [58].

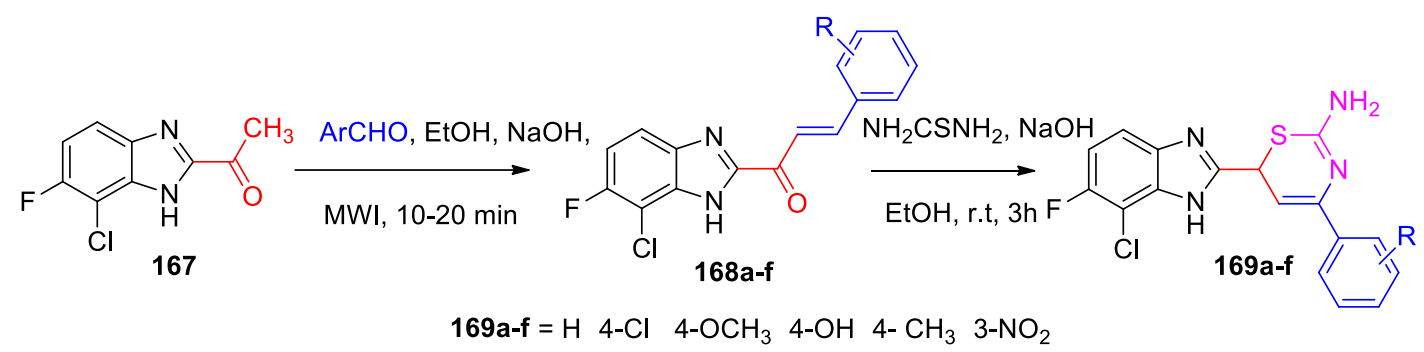

Scheme 57. Synthesis of benzimidazole linked pyrimidine 169a-f.

\subsection{Synthesis of the seven-membered rings.}

\subsubsection{Synthesis of diazepine.}

The benzimidazolylchalcones 170a-f on treatment with ethylenediamine 171 afforded the diazepines 172a-f under MWI condition (Scheme 58). The compounds were evaluated for antibacterial and antifungal activity in vitro. It was observed that all the compounds possess promising activity [59].

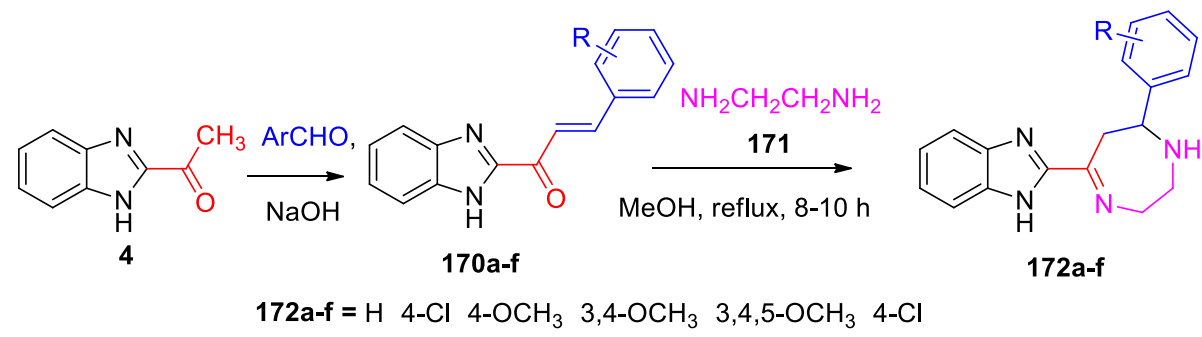

Scheme 58. Synthesis of benzimidazole linked diazepine 172a-f.

\subsubsection{Synthesis of fused rings.}

The reaction of benzimidazolylchalcones 173a-c with 2-amino thiophenol 174 in methanol containing few drops of acetic acid afforded 175a-c and subsequent oxidation of the former intermediate with chloranil produced benzothiazepine derivatives 176a-c (Scheme 59) [60].

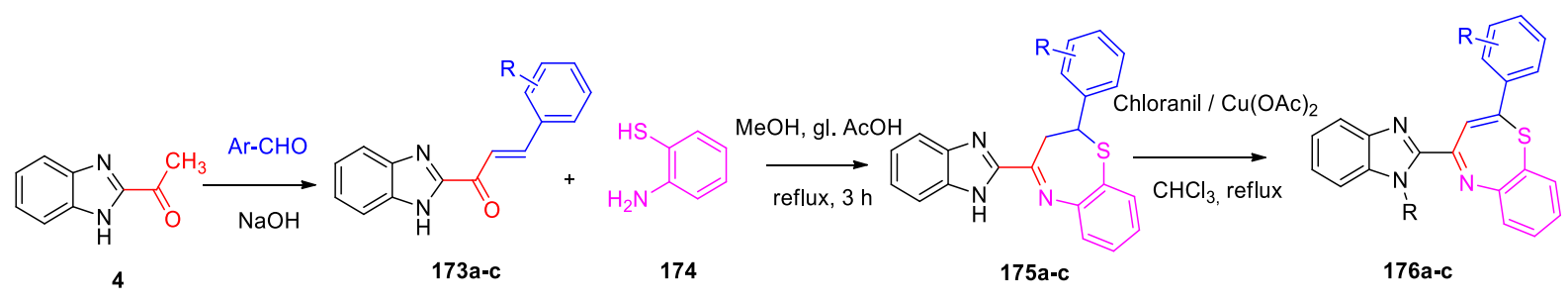

$176 \mathrm{a}-\mathrm{c}=\mathrm{H} 4-\mathrm{Cl} 4-\mathrm{OCH}_{3}$

Scheme 59. Synthesis of benzimidazole linked benzothiazepine 176a-c.

The chalcones 177a-g on treatment with bromine in acetic acid gave dibromo derivatives 178a-g which reacted with an o-phenylene diamine in sulphuric acid to furnish 2(benzimidazol-2-yl-methyl)-3-arylquinoxazolines 179a-g (Scheme 60) [46]. 


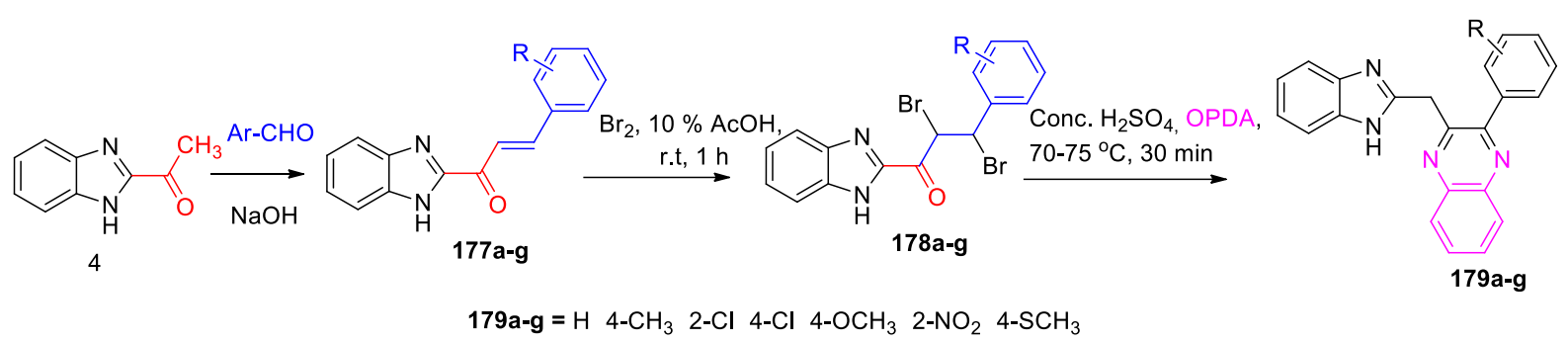

Scheme 60. Synthesis of benzimidazole linked quinoxazoline 179a-g.

Benzimidazolylchalcones 180a-f on reaction with ethyl acetoacetate in the presence of basic alumina gave 6-carboethoxy-3-benzimidazolyl-5-arylcyclohexenones 181a-f, which on treatment with hydrazine hydrate gave benzimidazole linked indazoles 182a-f under microwave-assisted condition (Scheme 61). The synthesized compounds were found to be active as antimicrobial [61].

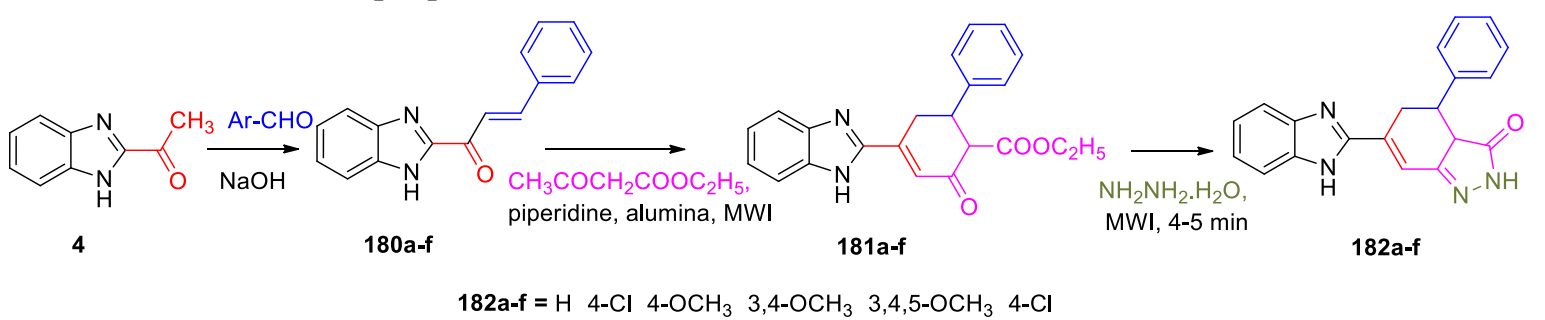

Scheme 61. Synthesis of benzimidazole linked indazole 182a-f.

2-acetyl benzimidazoles 183a-d on condensation reaction with 5-nitro furfural 184 at room temperature leads to the formation of chalcones 185a-d. These compounds on cyclo condensation reaction with triazole derivative $\mathbf{1 8 6}$ afforded benzimidazole linked triazolo[3,4b] $[1,3,4]$ thiadiazepines 187a-d (Scheme 62). These compounds were evaluated for their antibacterial and antifungal activity [62].

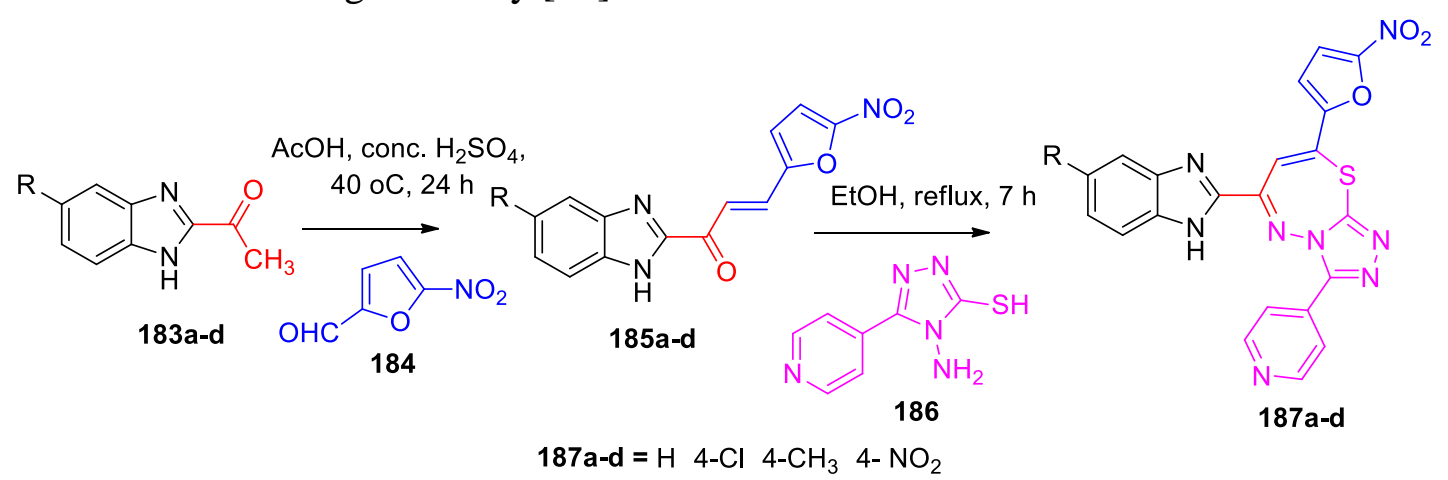

Scheme 62. Synthesis of benzimidazole linked triazolothiadiazepines 187a-d.

The chalcones 188a-d were reacted with bromine in carbon tetrachloride to yield dibromo adduct 189a-d. During recrystallization from methanol or acetic acid, the dibromo derivatives cyclized to give the pyrrolo[1,2-a]benzimidazoles 190a-d (Scheme 63) [53].

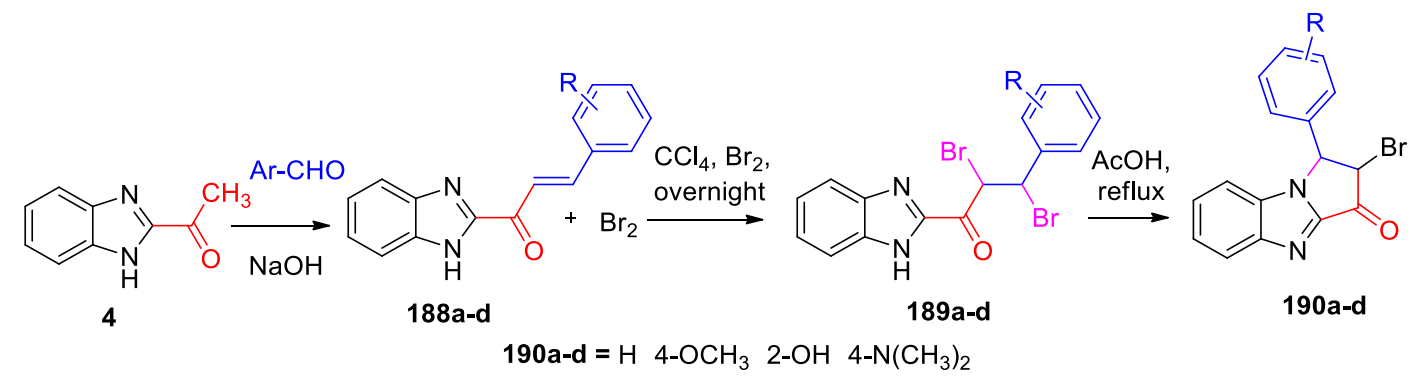

Scheme 63. Synthesis of benzimidazole linked pyrrolobenzimidazoles 190a-d. 


\subsection{Synthesis of Miscellaneous compound.}

A series of (2E)-1-(H-benzimidazol-2-yl)-3-substituted phenyl 2-propen-1-one embedded with barbitone 193a-e are prepared from chalcones 191a-e on reaction with barbituric acid 192 in the presence of acetic acid (Scheme 64). The synthesized compounds were screened for their antioxidant activity by the DPPH method and exhibited good antioxidant activity [63].

The compounds 193a-e, synthesized were further screened for their antiulcer activity in the pylorus-ligated rats and showed a percentage of protection of 67.17-69.56\% at a dose of $50 \mathrm{mg} / \mathrm{kg}$ body weight [64].

The same authors have also reported the antitumor activity for derivatives described above 193a-e against Dalton's ascitic lymphoma (DLA) in mice. They showed good antitumor activity at a dose of $50 \mathrm{mg} / \mathrm{kg}$ against DLA bearing mice [65].

The synthesized compounds 193 a-e also showed good antidepressant activity at a dose of $20 \mathrm{mg} / \mathrm{kg}$. The compounds 193 a-e considerably reduced the duration of immobility times [66].

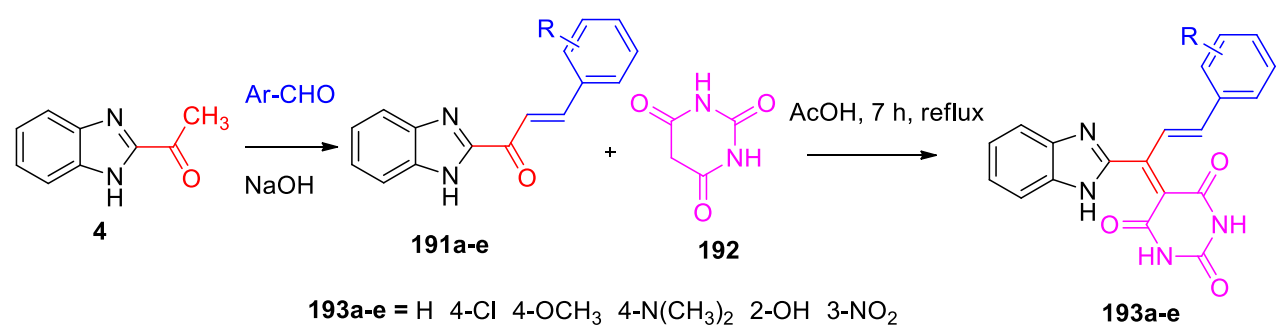

Scheme 64. Synthesis of benzimidazole linked barbitone 193a-e.

A series of some novel imines 196a-e were prepared (Scheme 65) by an acid-catalyzed nucleophilic addition reaction between 5-amino-1,3,4-thiadiazole-2-thiol 195 and heteroaryl chalcones 194a-e (Scheme 65). The compounds were screened for their antiulcer activity in the pylorus-ligated rats. Antioxidant activities of the derivatives were determined by DPPH method. Compounds showed a percentage of 70.43-73.47\% protection at a dose of $10 \mathrm{mg} / \mathrm{kg}$ body weight [67].

All the derivatives 196a-e were further screened for their hypnotic activity at a dose level of $10 \mathrm{mg} / \mathrm{kg}$ body weight. The compounds showed a significant percentage of an increase in sleeping time [68].

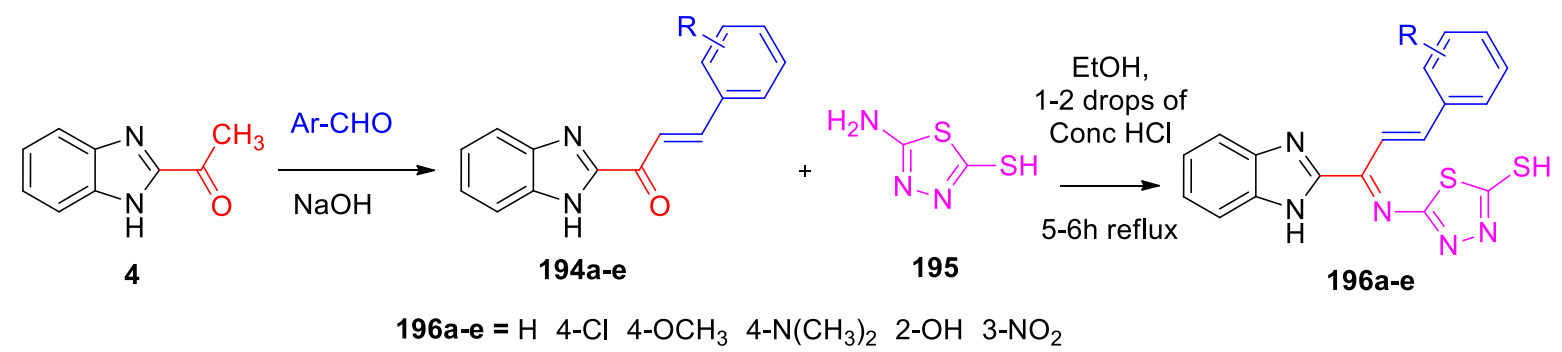

Scheme 65. Synthesis of benzimidazole linked thiadizole 196a-e.

Dubey et al. [69] investigated the Michael addition of various $\alpha, \beta$ - unsaturated benzimidazole chalcones 198a-f with nitromethane under solvent-free conditions in the presence of $\mathrm{K}_{2} \mathrm{CO}_{3}$ and $\mathrm{TBAB}$ as the surface catalyst by simple physical mixing in a mortar and pestle at room temperature gave the respective adducts 199a-f in good yields (Scheme 66). 

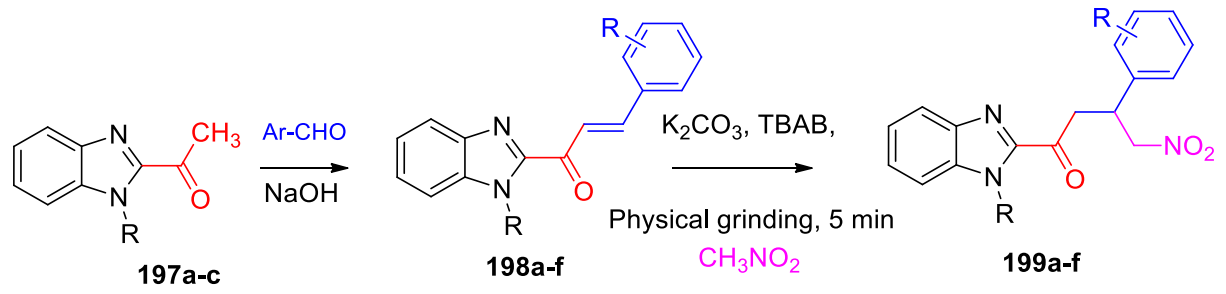

199a-f $=\mathrm{H} \quad 4-\mathrm{Cl} 4-\mathrm{OCH}_{3} \quad 4-\mathrm{CH}_{3} \quad 4-\mathrm{SCH}_{3} \quad 4-\mathrm{F}$

Scheme 66. Synthesis of benzimidazole derivatives 199a-f.

2-acetyl-1H-benzimidazole oxime-ethers 201a-f were synthesized from derivatives of 2acetylbenzimidazole 200a-b (Scheme 67). The antifungal activities of the compounds were determined against Botrytis cinerea and Alternaria alternata. Compounds 201b, 201c, 201f, 201g, and 201h exhibited good activities against Botrytis cinerea, while 201b and 201f possess excellent activities against Alternaria alternata [70].

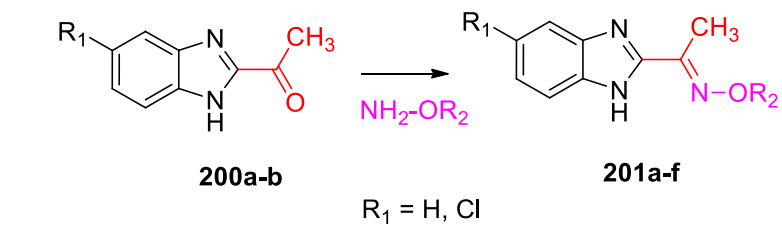

$\mathrm{R}_{2}=\mathrm{CH}_{3} \quad \mathrm{C}_{2} \mathrm{H}_{5} \quad \mathrm{n}-\mathrm{C}_{4} \mathrm{H}_{9} \quad \mathrm{CH}_{2} \mathrm{C}_{6} \mathrm{H}_{5} \quad 4-\mathrm{FC}_{6} \mathrm{H}_{4} \mathrm{CH}_{2} \quad 4-\mathrm{ClC}_{6} \mathrm{H}_{4} \mathrm{CH}_{2}$

Scheme 67. Synthesis of benzimidazole derivatives 201a-f.

Dihydropyrazino[1,2-a]benzimidazole 205a-j and 1-(2-arylvinyl)-3-arylpyrazino[1,2a] benzimidazole 206a-j were synthesized (Scheme 68 and 69), and their anti-cancer and antiHIV activities were determined. The compounds did not show anti-HIV activity, whereas significant anti-cancer activity was observed against leukemia cell lines [71].

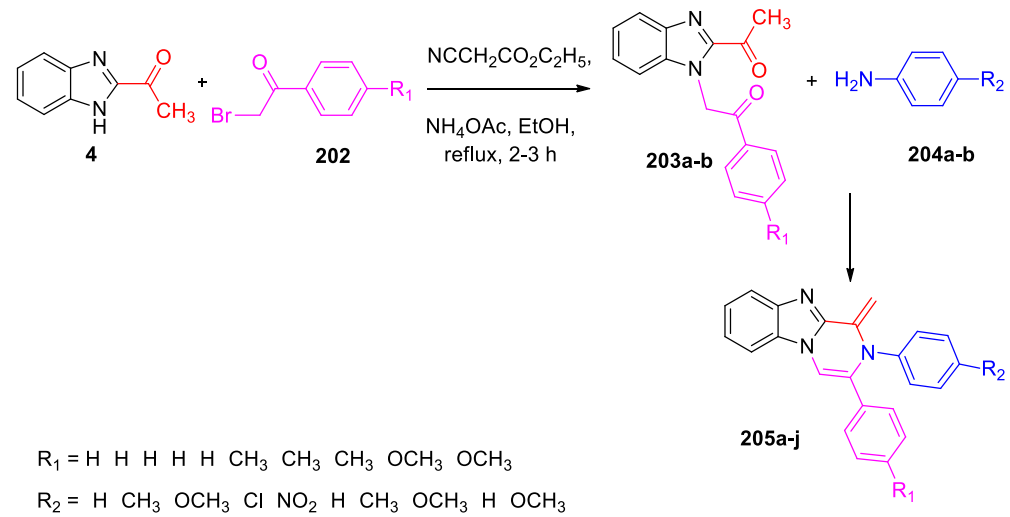

Scheme 68. Synthesis of benzimidazole derivatives 205a-j.

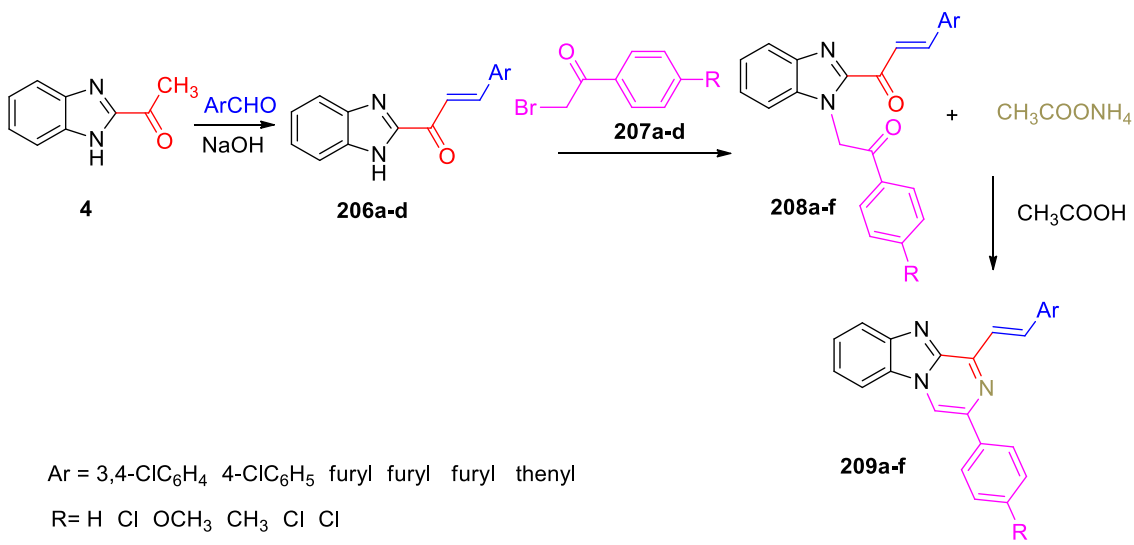

Scheme 69. Synthesis of benzimidazole derivatives 209a-f. 
Pyrazino[1,2-a] benzimidazole derivatives 214a-i possessing the $\mathrm{SO}_{2} \mathrm{CH}_{3}$ group were synthesized and evaluated for their anti-cancer, cyclooxygenase- 2 inhibitory, and anti-platelet aggregation activities (Scheme 70). Compound 214f was found to be the most potent COX-2 inhibitor with an $\mathrm{IC}_{50}$ value of $0.08 \mu \mathrm{M}$. Cytotoxicity of the compounds was also determined against the breast cancer cell line MCF-7. It was found that compound 214e exhibited the highest anti-proliferative activity. The compound $\mathbf{2 1 4 c}$ was found to be the most active platelet aggregation inhibitor [72].

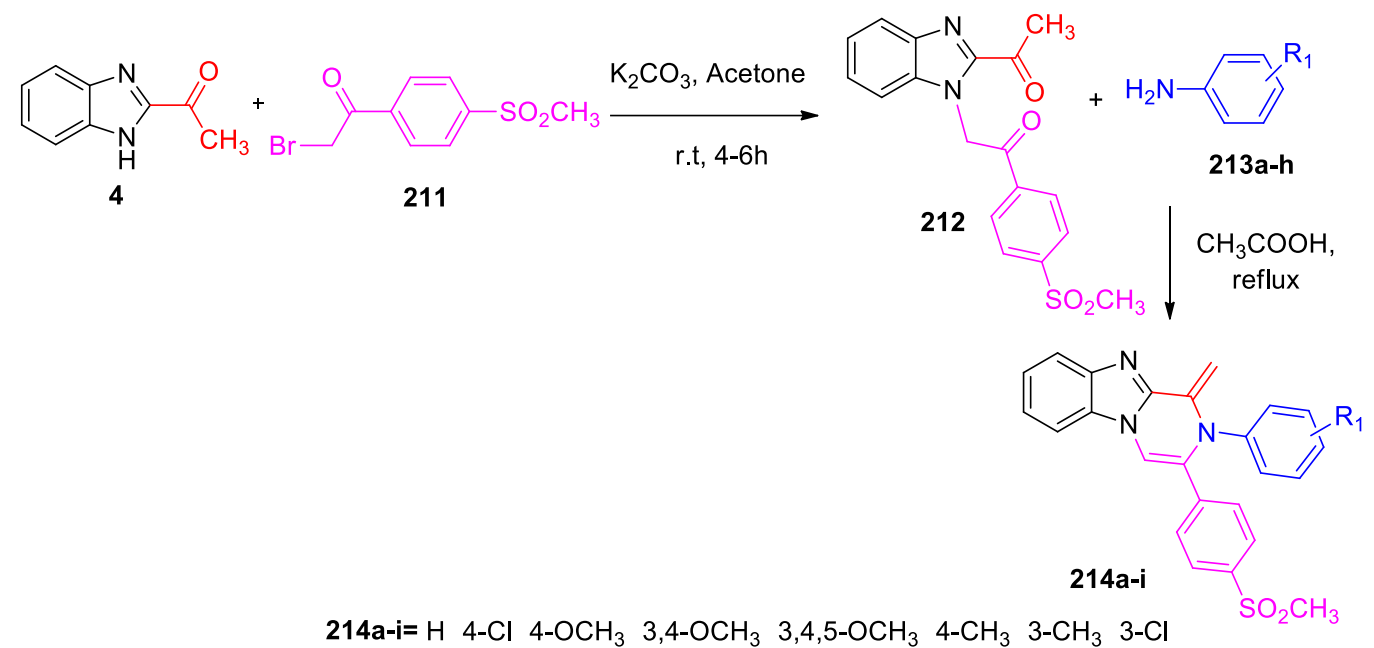

Scheme 70. Synthesis of benzimidazole derivatives 214a-i.

New pyrazino[1,2-a]benzimidazole derivatives 218a-h were synthesized and tested for their anti-cancer activity (Scheme 71). 2-acetylbenzimidazole was reacted with a derivative of $\alpha$-bromoacetophenones 215a-c using potassium carbonate in acetone to give 216a-c. These diketones were further reacted with varied benzylamines 217a-e in acetic acid to obtain 218ai. The remarkable anti-cancer activity was exhibited by compound 218e [73].

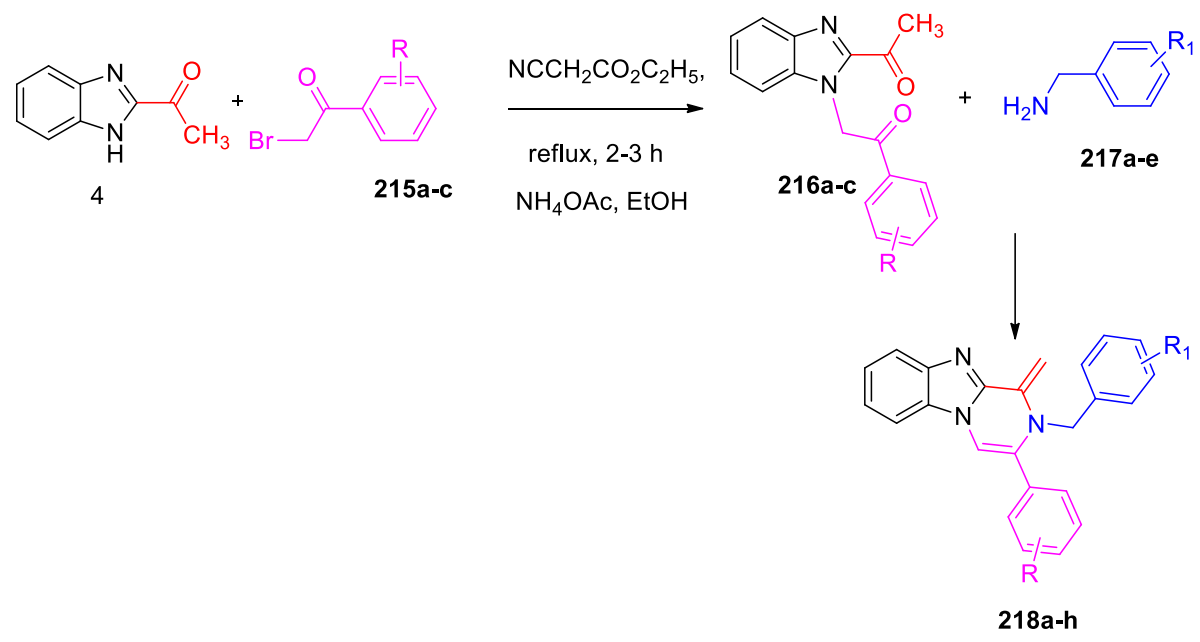

218a-h; R= H, H, H, H, H, 4- $\mathrm{OCH}_{3}, 4-\mathrm{OCH}_{3}, 3-\mathrm{Cl} \mathbf{R}_{1}=\mathrm{H}, 4-\mathrm{Cl}, 3-\mathrm{OCH}_{3}, 4-\mathrm{OCH}_{3}, 3-\mathrm{Cl}, \mathrm{H}$ 3-OCH, $4-\mathrm{OCH}_{3}$

Scheme 71. Synthesis of benzimidazole derivatives 218a-h.

Benzimidazoles incorporated with different heterocycles were synthesized, starting from 2-acetylbenzimidazole (Scheme 72). Candidates were evaluated for antimicrobial activity against Bacillus pumilus, Escherichia coli, Staphylococcus aureus, and Saccharomyces cerevisiae. Compound $\mathbf{2 2 3}$ was found to possess good activity against the tested bacteria with no antifungal activity [20]. 


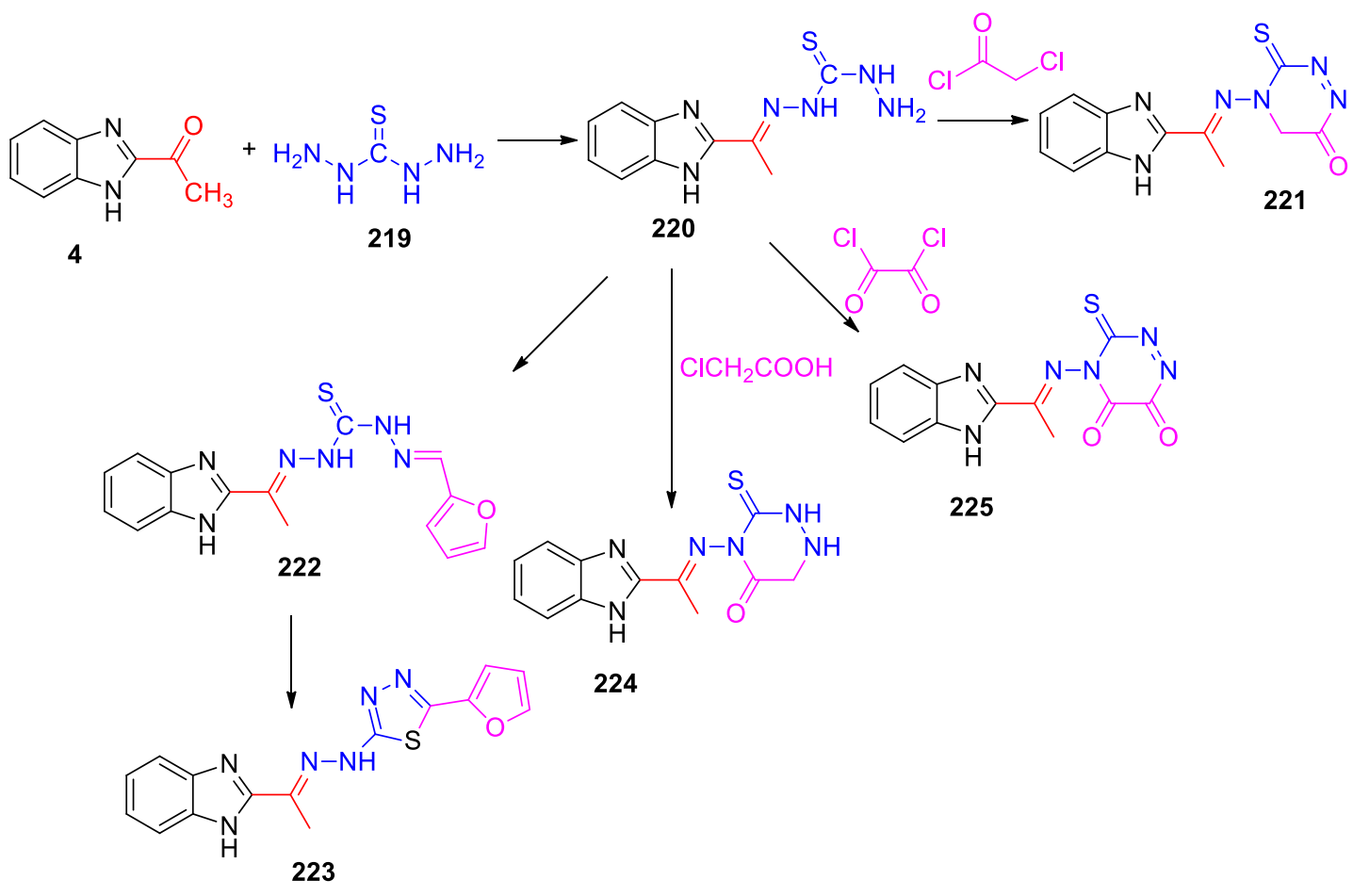

Scheme 72. Synthesis of benzimidazole derivatives 221-225.

\section{Conclusions}

2-Acetylbenzimidazole is easily accessible and contains a highly reactive keto and amino groups. This survey attempts to sum up the synthetic methods and reactions of 2acetylbenzimidazole during 1964-2020. The chemistry of 2-acetylbenzimidazole has shown promise on several fronts. The review revealed the wide synthetic applications of 2acetylbenzimidazole in organic synthesis, particularly in the synthesis of biologically useful heterocyclics such as oxirane, pyrazoline, and thiazole pyrazole, isoxazoline, isoxazole, pyridine, pyrimidine, thiazine, and diazepine. Most of the synthesized compounds exhibited good pharmacological activity.

\section{Funding}

The authors prepared the review article without any external funding.

\section{Acknowledgments}

Dr. Gopal Krishna Padhy would like to express his thanks to Dr. Chandra Sekhar Patro, Principal, School of Pharmacy, Centurion University of Technology and Management, Rayagada, Odisha, for his constant moral support during this work.

\section{Conflicts of Interest}

The authors declare no conflict of interest.

\section{References}

1. Kanwal, A.; Ahmad, M.; Aslam, S.; Naqvi, S.A.R.; Saif, M.J. Recent Advances in Antiviral Benzimidazole Derivatives: A Mini Review. Pharm. Chem. J. 2019, 53, 179-187, https://doi.org/10.1007/s11094-01901976-3. 
2. Yogita, B.; Manjinder, K.; Gulshan, B. Antimicrobial Potential of Benzimidazole Derived Molecules. MiniRev. Med. Chem. 2019, 19, 624-646, https://doi.org/10.2174/1389557517666171101104024.

3. Taha, M.; Rahim, F.; Zaman, K.; Selvaraj, M.; Uddin, N.; Farooq, R.K.; Nawaz, M.; Sajid, M.; Nawaz, F.; Ibrahim, M.; Khan, K.M. Synthesis, $\alpha$-glycosidase inhibitory potential and molecular docking study of benzimidazole derivatives. Bioorg. Chem. 2020, 95, 103555, https://doi.org/10.1016/j.bioorg.2019.103555.

4. Md. Jawaid, A.; Mohammad Shahar, Y.; Vinod Kumar, S.; Ahsan Ahmed, K.; Zulphikar, A.; Haider, M.D.R.; Ankita, P. Recent Progress of Benzimidazole Hybrids for Anticancer Potential. Curr. Med. Chem. 2020, 27, 5970-6014-, https://doi.org/10.2174/0929867326666190808122929.

5. Vemana, H.P.; Barasa, L.; Surubhotla, N.; Kong, J.; Ha, S.S.; Palaguachi, C.; Croft, J.L.; Yoganathan, S.; Dukhande, V.V. Benzimidazole scaffolds as potential anti-cancer agents: Synthesis and Biological evaluation. The FASEB Journal 2019, https://doi.org/10.1096/fasebj.2019.33.1_supplement.646.18. -

6. Hayrettin Ozan, G.; Açelya, M.; Mustafa Fethi, S.; Ilkay Erdogan, O. Benzimidazole-derived Compounds Designed for Different Targets of Alzheimer's Disease. Curr. Med. Chem. 2019, 26, 3260-3278, https://doi.org/10.2174/0929867326666190124123208.

7. Bukhari, S.N.A.; Lauro, G.; Jantan, I.; Fei Chee, C.; Amjad, M.W.; Bifulco, G.; Sher, H.; Abdullah, I.; Rahman, N.A. Anti-inflammatory trends of new benzimidazole derivatives. Future Med. Chem. 2016, 8, 1953-1967, https://doi.org/10.4155/fmc-2016-0062.

8. Cheeseman, G.W. 2-Acetylbenzimidazole. Royal Soc Chemistry Thomas Graham House, Science Park, Milton Rd, Cambridge: 1964; 4645.

9. Ramaiah, K.; Dubey, P.K.; Ramanatham, J.; Grossert, J.S.; Hooper, D.L. ChemInform Abstract: An Unusual Resistance to $\alpha$-Bromination by Arylacetyl Compound: Studies on Bromination of 2-Acetylbenzimidazoles and Their Subsequent Reactions with Sulfur Nucleophiles — Synthesis of Novel $\beta$-Ketosulfone Derivatives of Benzimidazoles. ChemInform 1999, 30, https://doi.org/10.1002/chin.199941120.

10. Kalirajan, R.; Rathore, L.; Jubie, S.; Gowramma, B.; Gomathy, S.; Sankar, S. Microwave assisted synthesis of some novel pyrazole substituted benzimidazoles and evaluation of their biological activities. Indian J. Chem. Sect. B 2011.

11. Kumar, P.K.; Dubey, P.K. Studies on preparation of 2-Acetylbenzimidazole. Der Pharma Chemica 2012, 4, 1292-1295.

12. Ouattara, M.; Sissouma, D.; Koné, M.W.; Menan, H.E.; Touré, S.A.; Ouattara, L. Synthesis and anthelmintic activity of some hybrid Benzimidazolyl-chalcone derivatives. Tropical Journal of Pharmaceutical Research 2011, 10, 767-775, https://doi.org/10.4314/tjpr.v10i6.10.

13. Mathew, B.; Unnikrishnan, G.; Shafeer, V.P.; Muhamed, M.C.; Femina, P. Microwave assisted synthesis, physicochemical properties and antimicrobial activity of benzimidazole chalcones. Der Pharma Chemica 2011, 3, 627-631.

14. Babu, I.; Selvakumar, S. An Antibacterial, Antifungal and Anthelmintic Evaluations of Some Synthesized Chalcone Derived Benzimidazoles. Biosciences Biotechnology Research Asia 2013, 10, 891-896.

15. Wu, L.-t.; Jiang, Z.; Shen, J.-j.; Yi, H.; Zhan, Y.-c.; Sha, M.-q.; Wang, Z.; Xue, S.-t.; Li, Z.-r. Design, synthesis and biological evaluation of novel benzimidazole-2-substituted phenyl or pyridine propyl ketene derivatives as antitumour agents. Eur. J. Med. Chem. 2016, 114, 328-336, https://doi.org/10.1016/j.ejmech.2016.03.029

16. Meshram, G.; Vala, V.; Wagh, P.; Deshpande, S. Ultrasound accelerated synthesis of novel benzimidazole derived chalcones as glucosidases inhibitor and antimicrobial agents. Indian J. Chem. Sect. B 2016, 55, 613623.

17. Sissouma, D.; Ouattara, M.; Kone, M.W. Synthesis and antifungal activities of some benzimidazolylchalcones, analogues of chlormidazole. African Journal of Pharmacy and Pharmacology 2015, 9, 418-423. https://doi.org/10.5897/ajpp2014.4171.

18. Meshram, G.A.; Vala, V.A. Synthesis, characterization, and antimicrobial activity of benzimidazole-derived chalcones containing 1,3,4-oxadiazole moiety. Chemistry of Heterocyclic Compounds 2015, 51, 44-50, https://doi.org/10.1007/s10593-015-1653-1.

19. Padhy, G.; Panda, J.; Behera, A. Synthesis and characterization of novel benzimidazole chalcones as antibacterial agents. Der Pharma Chemica 2016, 8, 235-241.

20. Abdel-Motaal, M.; Almohawes, K.; Tantawy, M.A. Antimicrobial evaluation and docking study of some new substituted benzimidazole-2yl derivatives. Bioorg. Chem. 2020, 101, 103972, https://doi.org/10.1016/j.bioorg.2020.103972.

21. Wu, L.; Yang, Y.; Wang, Z.; Wu, X.; Su, F.; Li, M.; Jing, X.; Han, C. Design, Synthesis, and Biological Evaluation of Aromatic Amide-Substituted Benzimidazole-Derived Chalcones. The Effect of Upregulating TP53 Protein Expression. Molecules 2020, 25, 1162., https://doi.org/10.3390/molecules25051162.

22. Djemoui, A.; Naouri, A.; Ouahrani, M.R.; Djemoui, D.; Lahcene, S.; Lahrech, M.B.; Boukenna, L.; Albuquerque, H.M.T.; Saher, L.; Rocha, D.H.A.; Monteiro, F.L.; Helguero, L.A.; Bachari, K.; Talhi, O.; Silva, A.M.S. A step-by-step synthesis of triazole-benzimidazole-chalcone hybrids: Anti-cancer activity in human cells+. J. Mol. Struct. 2020, 1204, 127487, https://doi.org/10.1016/j.molstruc.2019.127487. 
23. Dasari, G.K.; Sunkara, S.; Gadupudi, P.C.R. Green and ecofriendly synthesis of indole-condensed benzimidazole chalcones in water and their antimicrobial evaluations. J. Heterocycl. Chem. 2020, 57, 12011210, https://doi.org/10.1002/jhet.3856.

24. Hsieh, C.-Y.; Ko, P.-W.; Chang, Y.-J.; Kapoor, M.; Liang, Y.-C.; Chu, H.-L.; Lin, H.-H.; Horng, J.-C.; Hsu, M.-H. Design and synthesis of benzimidazole-chalcone derivatives as potential anti-cancer agents. Molecules 2019, 24, 3259, https://doi.org/10.3390/molecules24183259.

25. Nofal, Z.M.; Soliman, E.A.; Abd El-Karim, S.S.; El Zahar, M.I.; Srour, A.M.; Sethumadhavan, S.; Maher, T.J. Novel benzimidazole derivatives as expected anti-cancer agents. Acta Pol. Pharm. 2011, 68, 519-534.

26. Yar, M.S.; Abdullah, M.M.; Majeed, J. In vitro anti-tubercular screening of newly synthesized benzimidazole derivatives. World Acad. Sci. Engr. Tech 2009, 55, 593-599.

27. Shaharyar, M.; Abdullah, M.M.; Bakht, M.A.; Majeed, J. Pyrazoline bearing benzimidazoles: Search for anti-cancer agent. Eur. J. Med. Chem. 2010, 45, 114-119, https://doi.org/10.1016/j.ejmech.2009.09.032.

28. Cao, X.Q.; Lin, X.H.; Zhu, Y.; Ge, Y.Q.; Wang, J.W. The optical properties, synthesis and characterization of novel 5-aryl-3-benzimidazolyl-1-phenyl-pyrazoline derivatives. Spectrochimica Acta Part A: Molecular and Biomolecular Spectroscopy 2012, 98, 76-80, https://doi.org/10.1016/j.saa.2012.08.036.

29. Desai, N.C.; Pandya, D.D.; Joshi, V.V.; Rajpara, K.M.; Vaghani, H.V.; Satodiya, H.M. Synthesis, characterization and antimicrobial screening of hybrid molecules containing benzimidazole-pyrazole and pyridine nucleus. Med. Chem. Res. 2012, 21, 4463-4472, https://doi.org/10.1007/s00044-012-9990-4.

30. Desai, N.C.; Pandya, D.D.; Kotadiya, G.M.; Desai, P. Synthesis and characterization of novel benzimidazole bearing pyrazoline derivatives as potential antimicrobial agents. Med. Chem. Res. 2014, 23, 1474-1487, https://doi.org/10.1007/s00044-013-0756-4.

31. Rajora, J.; Yadav, J.; Kumar, R.; Srivastava, Y.K. ChemInform Abstract: Microwave Assisted Transformation of Benzimidazolyl Chalcones into N1-Substituted Pyrazolines and Evaluation of Their Antimicrobial Activities. ChemInform 2010, 41. https://doi.org/10.1002/chin.201047119.

32. Rajora, J.; Srivastava, Y. Eco friendly microwave assisted synthesis of some 3-benzimidazolyl -5- aryl-2pyrazolin -1- carboxaldehyde hydrazones as potent antimicrobial agents. Rasayan Journal of Chemistry 2009, 2, 641-644.

33. Padhy, G.K.; Panda, J.; Behera, A.K. Synthesis and characterization of novel benzimidazole embedded 1, 3, 5-trisubstituted pyrazolines as antimicrobial agents. J Serbian Chem. Soc. 2017, 82, 985-993, https://doi.org/10.2298/JSC160604089P.

34. Sharmila, A.; Shivakumar, B.; Gaviraj, E.N. Synthesis and evaluation of new pyrazolines of benzimidazole as potent analgesic and anti-inflammatory agents. Der Pharma Chemica 2016, 8, 33-37.

35. Saundane, A.R.; Mathada, K.N. Synthesis, characterization, and biological evaluation of some new chalcones containing indole moiety and their derivatives. Monatshefte für Chemie - Chemical Monthly 2016, 147, 1291-1301.

36. Bapna, A.; Ojha, S.; Talesara, G.L. ChemInform Abstract: Facile Synthesis of AlkoxyphthalimideDerivatized Benzimidazole-Assembled Pyrazoles, Pyrimidines and Isoxazoles, via Common Intermediate Chalcone. ChemInform 2008, 39, https://doi.org/10.1002/chin.200846118.

37. Sawhney, S.N.; Vir, D.; Gupta, A. Synthesis and Antiinflammatory Activity of Some 2-(5-Aryl-4, 5dihydropyrazol-3-yl)-and 2-(2-Amino-6-arylpyrimidin-4-yl) benzimidazoles. ChemInform 1991, 22, 11071112.

38. Paul, S.S.P.; Yardily, A.; Rajasekharan, K.N.; Abbs Fen Reji, T.F. ChemInform Abstract: Synthesis of Anticancer Compounds 2-(4-Amino-2-arylaminothiazol-5-oyl)-N-methylbenzimidazoles. ChemInform 2013, 44, https://doi.org/10.1002/chin.201330144.

39. Malla Reddy, V.; Ravinder Reddy, K. Synthesis and Antimicrobial Activity of Some Novel 4- $(1 \mathrm{H}-$ Benz[d]imidazol- 2yl)-1,3-thiazol-2-amines. Chem. Pharm. Bull 2010, 58, 953-956, https://doi.org/10.1248/cpb.58.953.

40. Eldebss, T.M.A.; Farag, A.M.; Shamy, A.Y.M. Synthesis of Some Benzimidazole-based Heterocycles and their Application as Copper Corrosion Inhibitors. J. Heterocycl. Chem. 2019, 56, 371-390, https://doi.org/10.1002/jhet.3407.

41. Rajora, J.; Srivastava, Y. Synthesis and antimicrobial activities of some benzimidazolyl pyrazoles. Rasayan Journal of Chemistry 2009, 2, 655-658.

42. Kumar, K.; Hemasunder, G.; Naidu, A.; Dubey, P.K. Alkylation studies on pyrazolyl and isoxazolyl benzimidazoles. Indian J. Heterocycl. Chem. 2011, 20, 393-398.

43. Arora, R.; Kaur, A.; Gill, N.S. Analgesic and anti-inflammatory activity of some newly synthesized novel pyrazole derivatives of benzimidazole. Curr. Res. Chem 2012, 4, 76-87, https://doi.org/10.3923/crc.2012.76.87.

44. Reddy, V.M.; Reddy, K.R. Synthesis and biological evaluation of some novel-3-(5-substituted benzimidazol-2-yl)-5-arylisoxazolines. Chin. Chem. Lett. 2010, 21, 1145-1148, https://doi.org/10.1016/j.cclet.2010.06.017.

45. Vekariya, N.A.; Khunt, M.D.; Parikh, A.R. Synthesis of Isoxazoles and Quinoxalines as Potential Anticancer Agents. ChemInform 2003, 34, https://doi.org/10.1002/chin.200322165. 
46. Yadav, J.S.; Srivastava, Y.K. A facile synthesis and antimicrobial activity of some new 2-subsituted benzimidazole derivatives carrying pyridine. Der Chemica Sinica 2011, 2, 1-7.

47. Maheswaran, N.; Saleshier, M.F.; Mahalakshmi, K.; Sureshkannan, V.; Parthiban, N.; Reddy, K.A. Synthesis And Characterisation Of 7-(1 H-Benzimidazol-2-Yl)-5-(Substituted Phenyl) Pyrido[2, 3-D] Pyrimidin-4-Amine For Their Biological Activity. International Journal of Chemical Sciences 2012, 10, 4351.

48. Desai, N.C.; Pandya, D.D.; Bhatt, K.A.; Kotadiya, G.M.; Priyanka, D. Synthesis, antimicrobial, and cytotoxic activities of novel benzimidazole derivatives bearing cyanopyridine and 4-thiazolidinone motifs. Med. Chem. Res. 2014, 23, 3823-3835, https://doi.org/10.1007/s00044-014-0971-7.

49. Desai, N.C.; Pandya, D.D.; Kotadiya, G.M.; Desai, P. Synthesis, antimicrobial and cytotoxic activity of 2azetidinone derivatives of pyridyl benzimidazoles. Med. Chem. Res. 2014, 23, 1725-1741, https://doi.org/10.1007/s00044-013-0775-1.

50. Rida, S.M.; El-Hawash, S.A.M.; Fahmy, H.T.Y.; Hazzaa, A.A.; El-Meligy, M.M.M. Synthesis of novel benzofuran and related benzimidazole derivatives for evaluation ofin vitro anti-HIV-1, anti-cancer and antimicrobial activities. Arch. Pharmacal Res. 2006, 29, 826-833, https://doi.org/10.1007/BF02973901.

51. Nofal, Z.M.; Srour, A.M.; El-Eraky, W.I.; Saleh, D.O.; Girgis, A.S. Rational design, synthesis and QSAR study of vasorelaxant active 3-pyridinecarbonitriles incorporating 1H-benzimidazol-2-yl function. Eur. J. Med. Chem. 2013, 63, 14-21, https://doi.org/10.1016/j.ejmech.2013.01.042.

52. Dubey, P.K.; Kumar, C.R.; Reddy, P.V.V. Syntheses of 1-alkyl-2-(substituted-2-pyridyl) benzimidazoles. Indian J. Chem. Sect. B 2003, 42, 2115-2118.

53. Zoorob, H.H.; Hammouda, H.A.; Ismail, E. Study of the Reactivity of 2-Cinnamoylbenzimidazole towards Thiourea, Urea, Hydrazines and Hydroxylamine Hydrochloride. Zeitschrift für Naturforschung B 1977, 32, 443-446, https://doi.org/10.1515/znb-1977-0419.

54. Ravinder Reddy, K.; Malla Reddy, V.; Srinivas, B. Synthesis And Characterization Of Some Novel 2-[(5Aryl)-4, 5-Dihydro-1h-Pyrazole-3-Yl]-1h-Benzimidazoles With Antimicrobial Activity. International Journal of Pharmaceutical Sciences and Drug Research 2014, 6.

55. Liu, H.-B.; Gao, W.-W.; Tangadanchu, V.K.R.; Zhou, C.-H.; Geng, R.-X. Novel aminopyrimidinyl benzimidazoles as potentially antimicrobial agents: Design, synthesis and biological evaluation. Eur. J. Med. Chem. 2018, 143, 66-84, https://doi.org/10.1016/j.ejmech.2017.11.027.

56. Padhy, G.K.; Panda, J.; Behera, A.K. Synthesis and Characterization of Novel N-Benzylbenzimidazole Linked Pyrimidine Derivatives as Anticancer Agents. Indian J. Pharm. Educ. Res. 2019, 53, S129-S134, https://doi.org/10.5530/ijper.53.2s.57.

57. Madawali, I.M.; Kalyane, N.V.; Gaviraj, E.N.; Shivakumar, B. Synthesis and Antimicrobial activity of some new Pyrimidines of 6-chlorobenzimidazoles. Oriental Journal of Chemistry 2018, 34, 1633, http://dx.doi.org/10.13005/ojc/340358.

58. Gayathri, B.; Hipparagi, S.M.; Ramjith, U.S.; Jacob, C.M. Microwave Assisted Synthesis of Fluoro, Chloro 2-Substituted Benzimidazole Thiazine Derivatives for Antibacterial and Analgesic Activities. Int. J. Res. Pharm. Sci. 2016, 2, 146-158.

59. Yadav, J.S.; Srivastava, Y. An efficient microwave assisted synthesis of some novel 1, 4 dizepine derivatives as possible antimicrobial agents. Rasayan Journal of Chemistry 2010, 3, 726-730.

60. Dubey, P.K.; Naidu, A.; Kumar, C.R.; Reddy, P.V.V. Preparation of 4-(1-alkyl-benzo [d] imidazole-2-yl)2-phenyl-2, 3 dihydrobenzo (b)[1, 4] thiazepines. Indian J. Chem. Sect. B 2003, 42, 1701-1705.

61. Yadav, J.S.; Rajora, J.; Srivastava, Y.K. Some transformations of benzimidazolyl chalcones using MAOS protocol-a green approach. Arch Appl Sci Res 2011, 3, 192-198.

62. Malla Reddy, V.; Ravinder Reddy, K. Synthesis and Antibacterial Activity of Some Novel 6-(1Hbenz[d]imidazol-2-yl)-8-(5-nitro-2-furyl)-3-(4-pyridyl)-7,8-dihydro $[1,2, \quad 4]$ triazolo $[3,4-b][1,3,4]$ thiadiazepines. Chem. Pharm. Bull 2010, 58, 1081-1084, http://dx.doi.org/10.1248/cpb.58.1081.

63. Mathew, B.; Suresh, A.J.; Anbazhagan, S. Microwave Assisted Synthesis, Physico-chemical Properties and Antioxidant Activity of a,b-Unsaturated Benzimidazole Derivatives Incorporated with Baritone Moiety. Asian J. Chem. 2013, 25, 1853-1856, https://doi.org/10.14233/ajchem.2013.13187.

64. Mathew, B.; Suresh, J.; Anbazhagan, S. Synthesis and PASS-assisted in silico approach of some novel 2substituted benzimidazole bearing a pyrimidine-2, 4, 6(trione) system as mucomembranous protector. $J$. Pharm. Bioallied Sci. 2013, 5, 39-43, https://doi.org/10.4103/0975-7406.106563.

65. Mathew, B.; Suresh, J.; Vinod, D. Antitumour activity of 5-[(2E)-1-(1H-benzimidazol-2-yl)-3-substituted phenylprop-2-en-1-ylidene] pyrimidine-2,4,6(1H,3H,5H)-triones against Dalton's ascitic lymphoma in mice. Med. Chem. Res. 2013, 22, 3911-3917, https://doi.org/10.1007/s00044-012-0407-1.

66. Mathew, B.; Suresh, J.; Anbazhagan, S. Development of novel (1-H) benzimidazole bearing pyrimidinetrione based MAO-A inhibitors: Synthesis, docking studies and antidepressant activity. Journal of Saudi Chemical Society 2016, 20, S132-S139, https://doi.org/10.1016/j.jscs.2012.09.015.

67. Mathew, B.; Suresh, J.; Anbazhagan, S.; Chidambaranathan, N. Discovery of some novel imines of 2-amino, 5-thio, 1,3,4-thiadiazole as mucomembranous protector. Synthesis, antioxidant activity and in silico PASS approach. Journal of Saudi Chemical Society 2016, 20, S426-S432, https://doi.org/10.1016/j.jscs.2013.01.002. 
68. Mathew, B.; Suresh, J.; Anbazhagan, S.; Devaraji, V. Hypnotic Profile of Imines from Benzimidazole Chalcones: Mechanism of Synthesis, DFT Studies and in silico Screening. Cent. Nerv. Syst. Agents Med. Chem. 2013, 13, 207-216, https://doi.org/10.2174/1871524914666140406135930.

69. Dubey, P.K.; Reddy, P.V.V.; Srinivas, K. An Expeditious "Green" Michael Addition of Nitro Methane to Benzimidazole Chalcones in the Presence of TBAB as Surface Catalyst. Lett. Org. Chem. 2007, 4, 445-447, https://doi.org/10.2174/157017807781467533.

70. Jiang, L.; Wang, H.; Mu, W.; Ji, Z.; Cao, P. Synthesis and Fungicidal Activity of 2-Acetyl-6-(un)substituted1H-benzimidazole Oxime-ethers. Chin. J. Chem . 2011, 29, 539-543, https://doi.org/10.1002/cjoc.201190119.

71. Demirayak, Ş.; Abu Mohsen, U.; Çağri Karaburun, A. Synthesis and anti-cancer and anti-HIV testing of some pyrazino[1,2-a]benzimidazole derivatives. Eur. J. Med. Chem. 2002, 37, 255-260, https://doi.org/10.1016/S0223-5234(01)01313-7.

72. Azami Movahed, M.; Daraei, B.; Shahosseini, S.; Esfahanizadeh, M.; Zarghi, A. Design, synthesis, and biological evaluation of new pyrazino[1,2-a]benzimidazole derivatives as selective cyclooxygenase (COX2) inhibitors. Arch. Pharm. 2019, 352, 1800265, https://doi.org/10.1002/ardp.201800265.

73. Demirayak, Ş.; Yurttaş, L. Synthesis and anti-cancer activity of some 1,2,3-trisubstituted pyrazinobenzimidazole derivatives. J. Enzyme Inhib. Med. Chem. 2014, 29, 811-822, https://doi.org/10.3109/14756366.2013.858142. 